San Jose State University

SJSU ScholarWorks

Mineta Transportation Institute Publications

$12-2020$

\title{
Development of a Statistical Model to Predict Materials' Unit Prices for Future Maintenance and Rehabilitation in Highway Life Cycle Cost Analysis
}

\author{
Changmo Kim \\ University of California, Davis \\ Ghazan Khan \\ California State University, Sacramento \\ Brent Nguyen \\ Mineta Transportation Institute \\ Emily L. Hoang \\ Mineta Transportation Institute
}

Follow this and additional works at: https://scholarworks.sjsu.edu/mti_publications

Part of the Statistical Models Commons, and the Transportation Commons

\section{Recommended Citation}

Changmo Kim, Ghazan Khan, Brent Nguyen, and Emily L. Hoang. "Development of a Statistical Model to Predict Materials' Unit Prices for Future Maintenance and Rehabilitation in Highway Life Cycle Cost Analysis" Mineta Transportation Institute Publications (2020). https://doi.org/10.31979/mti.2020.1806

This Report is brought to you for free and open access by SJSU ScholarWorks. It has been accepted for inclusion in Mineta Transportation Institute Publications by an authorized administrator of SJSU ScholarWorks. For more information, please contact scholarworks@sjsu.edu. 
SJSU

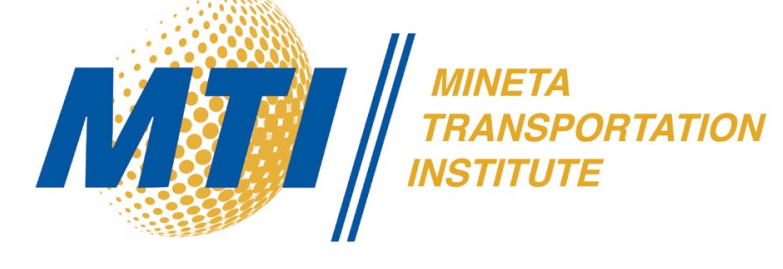

Development of a Statistical Model to Predict Materials' Unit Prices for Future Maintenance and Rehabilitation in Highway Life Cycle Cost Analysis

Changmo Kim, PhD

Ghazan Khan, PhD

Brent Nguyen

Emily L. Hoang

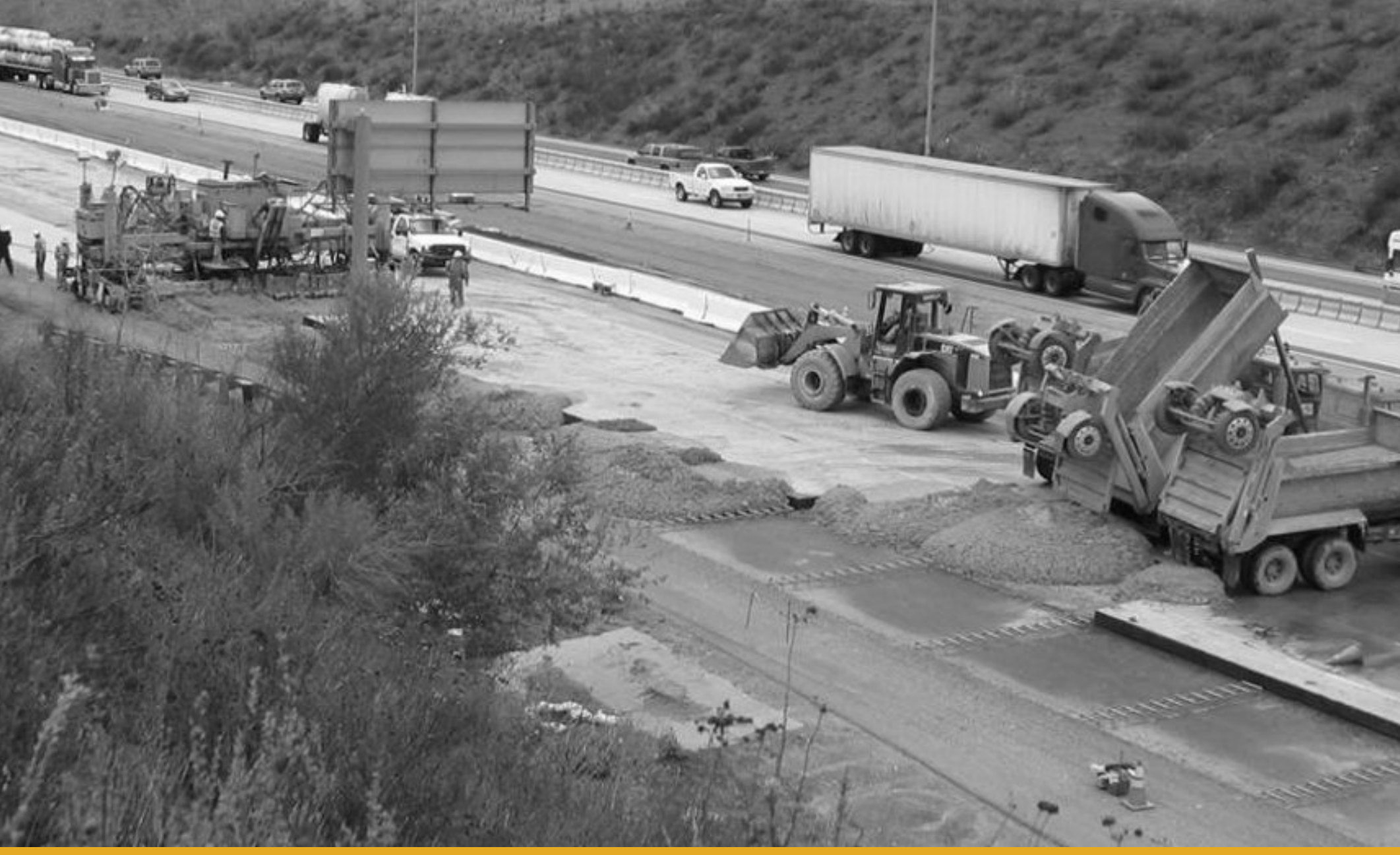




\section{MINETA TRANSPORTATION INSTITUTE}

Founded in 1991, the Mineta Transportation Institute (MTI), an organized research and training unit in partnership with the Lucas College and Graduate School of Business at San José State University (SJSU), increases mobility for all by improving the safety, efficiency, accessibility, and convenience of our nation's transportation system. Through research, education, workforce development, and technology transfer, we help create a connected world. MTI leads the Mineta Consortium for Transportation Mobility (MCTM) funded by the U.S. Department of Transportation and the California State University Transportation Consortium (CSUTC) funded by the State of California through Senate Bill I.MTI focuses on three primary responsibilities:

\section{Research}

MTI conducts multi-disciplinary research focused on surface transportation that contributes to effective decision making. Research areas include:active transportation; planning and policy; security and counterterrorism; sustainable transportation and land use; transit and passenger rail; transportation engineering; transportation finance; transportation technology; and workforce and labor. MTI research publications undergo expert peer review to ensure the quality of the research.

\section{Education and Workforce Development}

To ensure the efficient movement of people and products, we must prepare a new cohort of transportation professionals who are ready to lead a more diverse, inclusive, and equitable transportation industry. To help achieve this, MTI sponsors a suite of workforce development and education opportunities. The Institute supports educational programs offered by the Lucas Graduate School of Business: a Master of Science in Transportation Management, plus graduate certificates that include High-Speed and Intercity Rail Management and Transportation Security Management. These flexible programs offer live online classes so that working transportation professionals can pursue an advanced degree regardless of their location.

\section{Information and Technology Transfer}

MTI utilizes a diverse array of dissemination methods and media to ensure research results reach those responsible for managing change. These methods include publication, seminars, workshops, websites, social media, webinars, and other technology transfer mechanisms. Additionally, MTI promotes the availability of completed research to professional organizations and works to integrate the research findings into the graduate education program. MTI's extensive collection of transportation-related publications is integrated into San José State University's world-class Martin Luther King, Jr. Library.

\section{Disclaimer}

The contents of this report reflect the views of the authors, who are responsible for the facts and accuracy of the information presented herein. This document is disseminated in the interest of information exchange. MTl's research is funded, partially or entirely, by grants from the U.S. Department of Transportation, the U.S. Department of Homeland Security, the California Department of Transportation, and the California State University Office of the Chancellor, whom assume no liability for the contents or use thereof. This report does not constitute a standard specification, design standard, or regulation. 
REPORT 20-53

\title{
DEVELOPMENT OF A STATISTICAL MODEL TO PREDICT MATERIALS' UNIT PRICES FOR FUTURE MAINTENANCE AND REHABILITATION IN HIGHWAY LIFE CYCLE COST ANALYSIS
}

\author{
Changmo Kim, PhD \\ Ghazan Khan, PhD \\ Brent Nguyen \\ Emily L. Hoang
}

December 2020

A publication of

Mineta Transportation Institute

Created by Congress in 1991

College of Business

San José State University

San José, CA 95192-0219 


\section{TECHNICAL REPORT DOCUMENTATION PAGE}

1. Report No. 20-53

4. Title and Subtitle

Development of a Statistical Model to Predict Materials' Unit Prices for Future

Maintenance and Rehabilitation in Highway Life Cycle Cost Analysis
3. Recipient's Catalog No.

5. Report Date

December 2020

6. Performing Organization Code

8. Performing Organization Report CA-MTI-1806

10. Work Unit No.

11. Contract or Grant No. $65 \mathrm{~A} 0660$

13. Type of Report and Period Covered Final Report

14. Sponsoring Agency Code

\section{Supplemental Notes}

DOI: $10.31979 / \mathrm{mti} .2020 .1806$

\section{Abstract}

The main objectives of this study are to investigate the trends in primary pavement materials' unit price over time and to develop statistical models and guidelines for using predictive unit prices of pavement materials instead of uniform unit prices in life cycle cost analysis (LCCA) for future maintenance and rehabilitation (M\&R) projects. Various socio-economic data were collected for the past 20 years (1997-2018) in California, including oil price, population, government expenditure in transportation, vehicle registration, and other key variables, in order to identify factors affecting pavement materials' unit price. Additionally, the unit price records of the popular pavement materials were categorized by project size (small, medium, large, and extra-large). The critical variables were chosen after identifying their correlations, and the future values of each variable were predicted through time-series analysis. Multiple regression models using selected socio-economic variables were developed to predict the future values of pavement materials' unit price. A case study was used to compare the results between the uniform unit prices in the current LCCA procedures and the unit prices predicted in this study. In LCCA, long-term prediction involves uncertainties due to unexpected economic trends and industrial demand and supply conditions. Economic recessions and a global pandemic are examples of unexpected events which can have a significant influence on variations in material unit prices and project costs. Nevertheless, the data-driven scientific approach as described in this research reduces risk caused by such uncertainties and enables reasonable predictions for the future. The statistical models developed to predict the future unit prices of the pavement materials through this research can be implemented to enhance the current LCCA procedure and predict more realistic unit prices and project costs for the future M\&R activities, thus promoting the most cost-effective alternative in LCCA.

\section{Key Words}

Life Cycle Cost analysis, maintenance, rehabilitation, pavement materials, unit costs

\section{Distribution Statement}

No restrictions. This document is available to the public through The National Technical Information Service, Springfield, VA 22161
19. Security Classif. (of this report) Unclassified
20. Security Classif. (of this page)

Unclassified
21. No. of Pages

70
22. Price 


\title{
Copyright $\odot 2020$ \\ by Mineta Transportation Institute \\ All rights reserved
}

DOI: 10.31979/mti.2020.1806

\author{
Mineta Transportation Institute \\ College of Business \\ San José State University \\ San José, CA 95192-0219 \\ Tel: (408) 924-7560 \\ Fax: (408) 924-7565 \\ Email: mineta-institute@sjsu.edu
}

transweb.sjsu.edu 


\section{ACKNOWLEDGMENTS}

The authors thank the California Department of Transportation (Caltrans) for their support: in particular, Patrice Stafford, Kayo Lao, Tyler Monson, Joe Holland, and Nick Burmas with the Division of Research, Innovation and System Information, and Jonathan Hartog with District 8. The authors express their gratitude to the staff at MTI, including Executive Director Karen Philbrick, PhD; Deputy Executive Director Hilary Nixon, PhD; Graphic Designer Alverina Eka Weinardy; and Communication \& Operations Manager Irma Garcia. 


\section{TABLE OF CONTENTS}

$\begin{array}{ll}\text { Executive Summary } & 1\end{array}$

$\begin{array}{ll}\text { I. Introduction } & 3\end{array}$

Background 3

Research Objective and Tasks $\quad 3$

II. Literature Review $\quad 5$

Literature on Unit Price Estimation and Mathematical Models $\quad 5$

Review of Unit Price Data Sources from Various State Transportation Agencies 8

III. Data Collection and Analysis 10

California Pavement Construction Cost Data 10

Major and Minor Items for Pavement Maintenance and Rehabilitation Activity 10

Socio-Economic Parameters 12

IV. Model Development $\quad 25$

Variation in Pavement Material Unit Price by Geographical Location 25

Correlation in Socio-Economic Variables $\quad 26$

Time-Series Analysis of Socio-Economic Variables $\quad 27$

Multiple Regression Models for Predicting pavement Material Unit Price 30

$\begin{array}{ll}\text { V. LCCA Case Study } & 37\end{array}$

Description of the Case Study $\quad 37$

Unit Price of Pavement Materials 38

Life Cycle Agency Costs $\quad 39$

VI. Summary and Conclusion $\quad 41$

Appendix A: Socio-Economic Parameters (Past) 43

Appendix B: Socio-Economic Parameters

(Future Predicted) 44

Appendix C: Average Unit Prices of the Primary Pavement

Materials Used in for Future M\&R Activities in LCCA 46

Roadway Excavation (Unit: \$/CY) 46

Class 1 Aggregate Subbase (Unit: \$/CY) $\quad 47$

Class 2 Aggregate Subbase (Unit: \$/CY) 48

Class 3 Aggregate Subbase (Unit: \$/CY) 49 
Hot Mix Asphalt, Type A (HMA-A) (Unit: \$/Ton) 49

Hot Mix Asphalt, Open Graded (HMA-O) (Unit: \$/Ton) 49

Rubberized Hot Mix Asphalt, Type A (RHMA-A) (Unit: \$/Ton) 50

Rubberized Hot Mix Asphalt, Open Graded (RHMA-O) (Unit: \$/Ton) 50

Jointed Plain Concrete PAvement (JPCP) (Unit: \$/CY) 50

Jointed Plain Concrete PAvement, Rapid Setting Concrete (JPCP-RSC) (Unit: \$/CY) 51

Lean Concrete Base (LCB) (Unit: \$/CY) 51

Lean Concrete Base, Rapid Setting Concrete (LCB-RSC)

(Unit: $\$ / C Y)$

Appendix D: Predicted Unit Prices for Future M\&R Activities 53

Road Excavation, Unit Prices (\$/CY) 53

Class 3 Aggregate base, Unit Prices (\$/CY) 57

Hot Mix Asphalt, Type A (HMA-A), Unit Prices (\$/Ton) 59

Rubberized Hot Mix Asphalt, Gap Graded (RHMA), Unit Prices (\$/Ton) 61

Jointed Plain Concrete Pavement (JPCP), Unit Prices (\$/CY) 63

$\begin{array}{ll}\text { Abbreviations and Acronyms } & 65\end{array}$

$\begin{array}{ll}\text { Endnotes } & 66\end{array}$

$\begin{array}{ll}\text { Bibliography } & 68\end{array}$

$\begin{array}{ll}\text { About the Authors } & 70\end{array}$ 


\section{LIST OF FIGURES}

1. Unit Price Changes of Jointed Plain Concrete Pavement (JPCP) by Project Size in 2009-2018

2. California Gas Prices

3. Annual National Crude Oil Prices

4. California Population Growth (1970-2018) 20

5. The Past and the Future Predicted Values of Crude Oil 28

6. The Past and the Future Predicted Values of California Population 29

7. The Past and the Future Predicted Values of California Vehicle Registration 29

8. The Past and the Future Predicted Values of State Expenditure in Transportation

9. Average Unit Prices of Joint Plain Concrete Pavement by Project Size (2008-2018)

10. The Unit Price of HMA-A for the Past (Collected) and the Future (Predicted by Project Size)

11. The Unit Price of JPCP for the Past (Collected) and the Future (Predicted by Project Size) 


\section{LIST OF TABLES}

1. Example of Best-Value Award Algorithm from Typical Agencies

2. Summary of the Structural form for the Three Approaches to Model Variation in Bid Unit-Price Data

3. Pavement Unit Price Information by State

4. Pavement- and Non-Pavement-Related Items in Highway Construction

5. List of Primary Pavement Items used in Future M\&R in LCCA

6. State Annual Gas Price

7. National Crude Oil Price

8. California Vehicles Miles Travelled (VMT)

9. California Vehicle Registration

10. California Population Growth

11. Changes of Inflation Rates

12. California Budget Transportation Expenditure

13. California Minimum Wage

14. ANOVA Test Results of District and Climate variables for JPCP and HMA in 201826

15. Correlation Analysis Results for the Socio-Economic Parameters

16. The Results of the ARIMA Models

17. Maximum Quantities by Project Size for the Primary Pavement Materials Used in LCCA

18. Average Unit Prices of the Primary Pavement Materials by Project Size in 201832

19. The R-Squared Values and the Coefficients of the Variables in the Multiple Regression Models

20. Future M\&R Schedule of HMA Rehabilitation

21. Future M\&R Schedule of JPCP Rehabilitation 
22. The Uniform and the Predicted Unit Price and Net Present Values on the Activity Years for Alternative 1: HMA Rehab

23. The Uniform and the Predicted Unit Price and Net Present Values on the Activity Years for Alternative 2: JPCP Rehab

24. Life Cycle Agency Costs for Alternative 1: HMA Rehab

25. Life Cycle Agency Costs for Alternative 2: JPCP Rehab 


\section{EXECUTIVE SUMMARY}

Pavement Life Cycle Cost Analysis (LCCA) is a practice to help pavement designers make better decisions by balancing initial construction costs and projected future costs of a project. The future costs may include maintenance and rehabilitation (M\&R) costs as well as work zone traffic delay throughout the life cycle of a project.

LCCA has been used in California since 2007 to compare the cost-effectiveness of design alternatives such as pavement materials and cross-sections for Caltrans highway projects. The cost calculation module of the existing Caltrans LCCA software, RealCost 2.5CA, requires a unit price per material to calculate the cost of future M\&R projects. Caltrans' LCCA procedure manual guides users to default to the statewide uniform unit prices or find the relevant unit prices from the Caltrans historical contract cost database. However, materials' unit prices may vary over time given the project size or due to additional factors. The unit price entered by a user to calculate the future Maintenance and Rehabilitation (M\&R) project cost for a long-term LCCA period-typically 50-60 years-without considering unit price variability may result in inaccurate results.

Many state transportation agencies maintain construction cost data through public access webpages with unit price information made available for the past several years to several decades. This information is useful for contractors who prepare project bid documents and for pavement designers who compare design alternatives. Information in these resources provided useful guidance during this research and the authors' development of statistical models for LCCA unit price estimates in California.

The main objective of this research was to develop statistical models and guidelines for using predictive unit prices of pavement materials instead of uniform unit prices in LCCA for future M\&R activities. Developing predictive unit prices for future M\&R activities as an alternative method to the standard conception of unit pricing is a key contribution of the research. The research investigated the trends in the primary pavement materials' unit price and various California socio-economic parameters over time. The primary pavement materials' unit prices in the past 20 years (1999-2018) were collected from the Caltrans Construction Contract Cost database and trends were explored by geographical region (California districts), climate regions, as well as project size, to identify any differences related to such factors. The results showed no significant price differences by geographical or climate region, but differences were observed by project size. The unit prices of each pavement material were categorized into four project sizes (small, medium, large, and extra-large projects), and the annual average unit prices were calculated in each category. The project size was used as a binomial independent variable, and the unit prices were used as the dependent variable in multiple regression models. For most pavement materials, the unit price was lower in largesizes projects as compared to small-sized projects, therefore the addition of project size as an independent variable resulted in better prediction results in multiple regression models.

The research also investigated socio-economic parameters related to highway construction in order to identify factors that affect and can help predict future prices of pavement materials. Various socio-economic data describing California were collected, and after correlation analysis, four representative socio-economic parameters were selected: national crude oil 
price, California population, total number of the vehicles registered in California, and state budget expenditure in transportation. Data on these socio-economic variables were collected for the past 20 years (1997-2018), and their future values were predicted for a 50-year LCCA period using ARIMA time series models. The ARIMA model captured and smoothed the unique decline phenomenon of three socio-economic parameters, all except population, during the U.S. economic recession (approximately 2008-2012), and it predicted future values. The values of socio-economic variables (both current and predicted) were used as independent variables in multiple regression models to estimate each pavement material item's unit price for the future M\&R activities in the life cycle analysis period.

Using the pavement materials' unit prices from a Caltrans database as well as the socioeconomic data collected, multiple regression models were developed to estimate the annual unit prices of each pavement material for the next 50 years (2020-2069). The R-squared values for different variables were in the range of 0.5 and 0.9 indicating that the models were able to explain at least half or more of the variation in the response variables representing a good set of results. Although some of the predictions were realistic and reasonable, others were not considered satisfactory possibly due to a small number of years of past data or a small number of projects in certain size categories. For example, HMA-O's unit price was recorded for only four years from 2015 to 2018. Due to the lack of unit price information, the average unit price was not available in some project categories during the data collection period. The authors recommend using the latest unit prices of the materials having a lack of information instead of using the predicted unit prices in the model that might be biased. Conversely, the authors recommend the use of future unit prices predicted in the statistical models by project size of the pavement material items used in a large number of projects in the past years, such as Rowadway Excavation, Class 2 Aggregate Base, HMA-A, RHMA, JPCP, and LCB. These models were verified using the unit prices gathered from the recent pavement projects in the state.

The predicted future values of pavement materials' unit prices were used in a case study to compare the differences in the results obtained from using uniform unit prices in the current LCCA procedure. The NPVs of the life cycle agency costs calculated by the model-predicted unit prices were higher than those calculated with the uniform unit prices for two alternatives: HMA-A with a 20-year design life and JPCP with a 40-year design life. In the case study, JPCP with a 40-year design life was more cost-effective than HMA-A with 20-year design when the authors calculated the life cycle costs for both alternatives using the future unit prices predicted by the models developed in this study.

In LCCA, long-term prediction must take account of uncertainties due to the unexpected economic trends and industry demand and supply conditions. Economic recessions and a global pandemic are examples of unexpected events which can have a significant influence on variations in material unit prices and project costs in the future. Nevertheless, the datadriven scientific approach described in this research reduces the risk associated with such uncertainties and enables practicable predictions for the future. The models developed in this research can be implemented to enhance California's current LCCA procedure to predict more realistic unit prices and project costs for future M\&R activities, thus aiding in the selection of the most cost-effective alternatives within an LCCA framework. 


\section{INTRODUCTION}

\section{BACKGROUND}

Pavement life cycle cost analysis (LCCA) is a practice to help pavement designers make better decisions by balancing initial construction costs and projected future costs of a project. The future costs may include maintenance and rehabilitation (M\&R) costs and work zone traffic delay throughout the life cycle of a project. ${ }^{1}$ In 2002, the Federal Highway Administration (FHWA) first published an LCCA primer to provide background knowledge and demonstrations for transportation officials, and that was followed by an LCCA software tool in 2004 called RealCost (version 2.5) to support practitioners performing LCCA for highway projects. ${ }^{2,3}$

LCCA has been used in California since 2007 to compare the cost-effectiveness of design alternatives such as paving materials and cross-sections for Caltrans highway projects. ${ }^{4,5}$ According to the Caltrans Highway Design Manual (HDM) Topics 612 and 619, Caltrans pavement engineers evaluate the cost-effectiveness of alternative pavement designs for new construction, reconstruction, and rehabilitation of highways. ${ }^{6}$ To support the project engineers, Caltrans published the Life Cycle Cost Analysis Procedure Manual in 2007, which was updated in 2013. Additionally, an online training course was developed and is available on the Caltrans LCCA website. ${ }^{4}$

The cost calculation module of the existing Caltrans LCCA software, RealCost 2.5CA, requires a unit price per material to calculate the cost of future M\&R projects. Caltrans' LCCA procedure manual guides users to defer to the statewide uniform unit prices as a default or to find the relevant unit prices from the Caltrans historical contract cost database. ${ }^{1}$ However, materials' unit prices may vary over time given the project size or due to additional factors. Entering a unit price to calculate the future M\&R project cost for a long-term LCCA period (typically 60 years) without considering unit price variability may yield inaccurate results. ${ }^{7}$

\section{RESEARCH OBJECTIVE AND TASKS}

The objective of this research was to investigate the trends in pavement materials' unit prices due to various factors (project size, climate region, and other socio-economic variables) and develop statistical models to predict material and construction-related unit price inputs for future M\&R projects to support LCCA for California highway projects. Developing the future predictive unit prices as an alternative method to the standard conception of future uniform unit pricesis a key contribution of this study. The study results will enhance the accuracy and practicality of the highway LCCA results with the aim of enabling practitioners to select cost-effective material and construction alternatives. In view of the objectives, the following list of tasks were completed in this research.

\section{Task 1: Development of Research Framework and Literature Review}

A review of the published research, state Department of Transportation resources, and tools related to state-of-the-art practices used to estimate materials and construction costs for highway maintenance and rehabilitation projects was conducted. Various 
sources of data were also identified to be used in subsequent tasks in this research.

\section{Task 2: Data Collection and Analysis}

The materials and construction costs of California highway projects were collected from the Caltrans contractor cost database and the Integrated Maintenance Management System (IMMS) database..$^{8}$ Additional data on various factors that may impact materials' unit price were also collected from several sources. All data were integrated in a database at a local server and analyzed using open-source software tools.

\section{Task 3: Model Development}

The unit cost estimate models were developed from the collected data using appropriate statistical methods (categorical analysis, cluster analysis, and multiple linear/non-linear regression). Various models were developed and tested to identify the most relevant model in this research.

\section{Task 4: Model Validation and Case Study}

The statistical models developed in this research was applied to a recent Caltrans project as a case study to evaluate model effectiveness and the sensitivity of model output. The future unit prices predicted by the statistical models were used in the project cost calculation for the future M\&R activities and compared with the project costs calculated by the standard concept of the uniform unit prices for the future M\&R activities.

\section{Task 5: Documentation and Final Report}

A final report was prepared documenting all findings of the research and final recommendations to Caltrans. 


\section{LITERATURE REVIEW}

\section{LITERATURE ON UNIT PRICE ESTIMATION AND MATHEMATICAL MODELS}

The process for estimating pavement project cost usually consists of many individual elements combined to obtain the final cost output. Although the methods used throughout the United States vary, there are certain elements and variables that are common to most, if not all, methods. In general, the engineer determines the unit price basis based on the proposed scope for the project considering the following factors:

- Geographic location (e.g., urban/rural, state location, district),

- Similarity of recent construction projects,

- Inflation (adjustments of past prices to reflect the current year),

- Reliability of recent construction cost data,

- Recent trends in cost of materials, labor, and equipment,

- Anticipated difficulty of construction,

- Project size relative to size of previous projects,

- Proposed project schedule,

- Anticipated construction staging,

- Right-of-way,

- Railroads,

- Utilities,

- Expected environmental problems (e.g., hazardous wastes, wetlands), and

- Engineering judgment.

Several research studies have been conducted to explore pavement cost estimate approaches and methodologies in the past two decades. Gransberg and Molenaar developed the life cycle cost award algorithms for a design/build highway pavement project in 2003. ${ }^{9}$ The study goal was to design best-value award algorithms based on the best sustaining lifespan to procure pavement versus conventional lowest bid awards. Gransberg and Molenaar analyzed the existing design/build award methods to identify the potential for applying awards based on the life cycle award algorithms (LCAA). ${ }^{9}$ In addition to the initial capital cost, the algorithm proposed a new requirement applicable among design/builders to consider maintenance, repair, and rehabilitation costs. 
The analysis focused on two cases: one was administered through the Florida Department of Transportation (FDOT) and the other through the Washington State Department of Transportation (WSDOT). The FDOT case was based on literature in FDOT's design/ build policy documentation ${ }^{10}$ considering proposals, costs, and scheduling corresponding with technical scores, all applicable to best-value award algorithms. The WSDOT case was based on an urban freeway project in Vancouver, Washington, State Route 500: the "Thurston Way Interchange Project." This was WSDOT's first design/build project, with grade-separated structures, on/off ramps, and realignment. Eight 12-ft lanes were analyzed based on AASHTO 1993 definitions. Design alternatives were referenced from the existing state manuals and material costs for LCAA. ${ }^{9}$ To eliminate external variables, the researchers assumed that the projects were purely pavement construction projects excluding non-pavement related projects like drainage or traffic signage projects.. Only pavement structure from the sub-grade up was included in the analysis, and the subgrade was assumed to be the same for all alternatives. Cost was analyzed by life cycle unit of cost per centerline-mile to evenly account for construction work zones and roadway curvatures. The work zone was assumed to be one mile in length, and it was assumed that no more than half of the available lanes were closed at any given time per requests for proposals (RFPs) traffic control requirements. ${ }^{9}$

Gransberg and Molenaar found four different categories of best-value award algorithms in state highway design/build RFPs.

- Meets technical criteria-low bid;

- Adjusted bid;

- Adjusted score; and

- Weighted criteria.

Several other states (Arizona, Indiana, South Carolina, Texas, and Washington) also had a specified formula and score consideration for the award algorithms, as summarized in Table 1. 
Table 1. Example of Best-Value Award Algorithm from Typical Agencies ${ }^{9}$

\begin{tabular}{|c|c|c|}
\hline Agency & Formula with Agency Name for Award Method & Award Algorithm \\
\hline $\begin{array}{l}\text { Arizona DOT (AZDOT } \\
\text { 1997) }\end{array}$ & Adjusted price $=$ price proposal - quality value & Adjusted bid \\
\hline $\begin{array}{l}\text { Indiana DOT (INDOT } \\
\text { 1998) }\end{array}$ & $\begin{array}{l}\text { Low bid - fully qualified } \\
\text { Fully qualified }=\text { score } \geq 75\end{array}$ & $\begin{array}{l}\text { Meets technical } \\
\text { criteria - low bid }\end{array}$ \\
\hline $\begin{array}{l}\text { Federal Highway } \\
\text { Administration (FHWA } \\
\text { 2001) }\end{array}$ & $\begin{array}{c}\text { Adjusted score }=\text { technical score } \mathrm{x} 10,000 / \text { price proposal }+ \\
\text { contract administrative } \operatorname{cost}^{\dagger} \\
{ }^{\dagger} \text { Contract administrative cost }=\text { daily administrative cost } \mathrm{x} \\
\text { proposed schedule days }\end{array}$ & Adjusted score \\
\hline $\begin{array}{l}\text { South Carolina DOT } \\
\text { (SCDOT 1996) }\end{array}$ & Composite score $=$ price proposal/technical score & Adjusted bid \\
\hline $\begin{array}{l}\text { Texas Turnpike Authority } \\
\text { (TTA 2001) }\end{array}$ & $\begin{array}{l}\text { Price score }=\left(\text { lowest proposed price } / \text { price }_{i}\right) \times \mathrm{Wt}_{\text {price }} \\
\text { Technical score }=\left(\text { tech score }{ }_{i} / \text { high tech score }\right) \times W_{\text {tech }}\end{array}$ & Weighted criteria \\
\hline $\begin{array}{l}\text { Washington DOT (WSDOT } \\
\text { 1999) }\end{array}$ & $\begin{array}{c}\text { Best-value score } \\
\text { Technical score } \times 10,000,000 \text { / lump sum price }\end{array}$ & Adjusted score \\
\hline
\end{tabular}

Gransberg and Molenaar's study concluded that the best-value award algorithm can be skewed based on cost, time, or quality. It is possible to use LCAA, but the processes must be followed through thoughtfully to prevent bias towards other factors that may affect contractors and owners alike.

Tighe presented the guidelines for a probabilistic pavement life cycle cost analysis procedure. ${ }^{11}$ Tighe's guidelines followed the same principles as discussed in the LCAA developed by Gransberg. ${ }^{9}$ Specifically, for Tighe's LCAA, it was recommended that constant dollars and real discount rates be used, thus eliminating estimates and premiums for both cost and discount rates. Pavement cost estimates were determined by the availability of data from previous construction and maintenance projects. The initial construction, major maintenance, rehabilitation, and salvage values were used for the LCAA. Initial construction included material costs with pavement design. Maintenance costs were categorized as routine maintenance, such as pothole repair or drainage improvements, and major maintenance such as structure and surface improvements. Rehabilitation cost was determined from pavement performance prediction, and salvage value was included at the end of service life to calculate salvage values of the material. For the cost variation analysis, the goodness of fit test was utilized to examine the distribution of the data across the material types and costs. Costs from bidders were also compiled based on bidding prices and were analyzed graphically to observe the most common pricing for the specific material per unit weight. Depending on the data spread, either a log normal or a normal distribution was applied to fully quantify the material's statistical behavior. For the pavement thickness variation, it was suggested that a best fit distribution should be utilized given limited information in the prior literature. ${ }^{11}$

Tighe's guidelines followed an in-depth mathematical model based on the Monte Carlo simulation to better simulate the true probability distribution for a certain frequency for each material usage. Tighe suggested that for the overall analysis of pavement LCCA, a log normal distribution should be used for most of the components relating to the material's cost and cost of construction, thus better quantifying the variations and statistical spread with varying bidding and economic changes. ${ }^{11}$ 
Swei et al. presented a parametric approach to estimate expected cost and cost variation in infrastructure construction by utilizing a probabilistic LCCA procedure. ${ }^{12}$ The study utilized fifteen different pavement bid items across five American states and specifically investigated the bias and heteroscedasticity in what were then current cost-estimation procedures. Several methods were utilized, including multiple linear regression, reiteration of data, logarithmic, transformation, and other approaches, as summarized in Table 2. The mathematical functional forms were then applied to each individual state and its corresponding bid datasets.

Table 2. Summary of the Structural form for the Three Approaches to Model Variation in Bid Unit-Price Data ${ }^{12}$

\begin{tabular}{ccc}
\hline Approach & Model Type & Functional Form \\
\hline 1. & Log & Reciprocal \\
& Power & $P_{i}=\beta_{o}+\beta_{q} L N\left(\chi_{i, q}\right)+u_{i}$ \\
& & $\frac{1}{P_{i}}=\beta_{0}+\beta_{q} \chi_{i, q}+u_{i}$ \\
2. & Box-Cox transformation $(\lambda)$ & $L N\left(P_{i}\right)=\beta_{0}+\beta_{q} L N\left(\chi_{i, q}\right)+u_{i}$ \\
& & $P_{i}^{\left(\lambda_{1}\right)}=\beta_{0}+\beta_{q} \chi_{i, q}^{\left(\lambda_{2}\right)}+u_{i}$ \\
3. & $\begin{array}{c}\text { Box-Cox transformation }(\lambda), \text { district variation } \\
(d), \text { and number of bidders }(b)\end{array}$ & $P_{i}^{\left(\lambda_{1}\right)}=\beta_{0}+\beta_{q} \chi_{i, q}^{\left(\lambda_{2}\right)}+\sum_{l=1}^{L} \beta_{d_{l}} \chi_{i, d_{l}}+\beta_{b} \chi_{i, b}+u_{i}$ \\
\hline
\end{tabular}

Notes:

$P_{i}$ : Bid unit, i.e., price for $i^{\text {th }}$ sample

$\chi_{i, q}$ : Bid quantity

$\chi_{i, d_{l}}$ : Dummy variable for $l^{\text {th }}$ district within a state

$\chi_{i, q}$ : Number of bidders for a project

$\lambda_{1}, \lambda_{2}$ : Optimal data transformations for bid unit price and quantity

Conclusively, Swei and colleagues found that current methods of LCCA result in biased estimates, but applying principles of maximum likelihood can reduce the bias naturally present in material and construction costs. ${ }^{12}$

\section{REVIEW OF UNIT PRICE DATA SOURCES FROM VARIOUS STATE TRANSPORTATION AGENCIES}

A detailed review of unit price database from nine state transportation agencies was conducted in order to understand the information being utilized by those agencies in their respective processes. Table 3 provides a list of the data sources from each of the nine state transportation agencies. Many agencies maintain this information through public access webpages with unit price information for the past several years to decades available. This information is useful for contractors who prepare project bid documents and for pavement designers who compare design alternatives. Information in these resources provided useful guidance and ideas during this research in order to identify critical socio-economic factors to help develop statistical models for California LCCA unit price estimates. 
Table 3. Pavement Unit Price Information by State

\begin{tabular}{|c|c|}
\hline State & Source, Format, Description, and Link \\
\hline California & $\begin{array}{l}\text { DOT website, web interface, downloadable to csv files } \\
\text { https://sv08data.dot.ca.gov/contractcost/ }\end{array}$ \\
\hline Colorado & $\begin{array}{l}\text { Item Unit Costs by Projects, } 2015 \text { Cost Data, Data source: DOT website; pdf file } \\
\text { https://www.codot.gov/business/eema/documents/2015/2015-cdb-1st-qtr/view }\end{array}$ \\
\hline Connecticut & $\begin{array}{l}\text { CTDOT English Bid Item List (Unit Prices), December } 2018 \\
\text { Data source: DOT website; Excel sheet } \\
\text { https://www.ct.gov/dot/cwp/view.asp?a=3198\&q=459664 }\end{array}$ \\
\hline Florida & $\begin{array}{l}\text { Bridge construction and demolition unit price per square feet } \\
\text { Data from April 2014, Data source: DOT website; pdf file } \\
\text { http://www.dot.state.fl.us/planning/policy/costs }\end{array}$ \\
\hline Kentucky & $\begin{array}{l}\text { Average Unit Bid Prices, Data from 2016, 2017, and } 2018 \\
\text { Data source: DOT website; Excel sheets } \\
\text { https://transportation.ky.gov/Construction-Procurement/Pages/Average-Unit-Bid-Prices.aspx }\end{array}$ \\
\hline New York & $\begin{array}{l}\text { US Customary Contracts Let April 1, } 2016 \text { to March 31, } 2017 \\
\text { Weighted Average Unit Price Report, By Item, Region and Quarter } \\
\text { Data source: DOT website; Excel sheet, Microsoft Word and pdf files } \\
\text { https://www.dot.ny.gov/divisions/engineering/design/dqab/waipr }\end{array}$ \\
\hline Texas & $\begin{array}{l}\text { Average Low Bid Unit Prices - Construction and Maintenance, March } 2019 \\
\text { Highway Cost Index Report, April } 2019 \\
\text { Data source: DOT website; Excel sheet, text document, and pdf file } \\
\text { https://www.txdot.gov/business/letting-bids/average-low-bid-unit-prices.html }\end{array}$ \\
\hline West Virginia & $\begin{array}{l}\text { Highway Construction Unit Prices }(2016,2017,2018) \text {, } \\
\text { DOT website; text document } \\
\text { https://transportation.wv.gov/highways/contractadmin/Lettings/Pages/AverageUnitBidPrices. } \\
\underline{\text { aspx }}\end{array}$ \\
\hline Wisconsin & $\begin{array}{l}\text { Average Unit Price List, December 2018, Cost Index Data, July } 2016 \\
\text { Data source: DOT website; Excel sheet and pdf file } \\
\text { https://wisconsindot.gov/Pages/doing-bus/eng-consultants/cnsltrsrces/ } \\
\text { tools/estimating/est-guidance.aspx }\end{array}$ \\
\hline
\end{tabular}




\section{DATA COLLECTION AND ANALYSIS}

In view of the literature and considering the research objectives, the research team investigated various sources of information related to Caltrans highway projects and maintenance costs to obtain pavement construction cost data. Caltrans maintains the Integrated Maintenance Management System (IMMS) database which includes the project date, location, size, cost, material quantity and unit price, and equipment quantity and unit price for past projects completed on the California highway system. Additionally, Caltrans' Contractor Cost database ${ }^{8}$ and Annual Contract Cost Data Books ${ }^{13}$ contain information on contractors' bid costs per item for all projects which can be filtered by district, year, minimum and maximum price, and quantity. Data on California Highway Capital Maintenance (CAPM) and Rehabilitation (REHAB) projects completed in the past 20 years were collected from these sources for use in this research.

Relevant data were exported and integrated into a new local database on a local server with additional socio-economic parameters. Data on the socio-economic parameters collected and utilized in this research included gasoline/diesel price, population, crude oil price, annual state budget in construction, the number of vehicles registered in California, annual vehicle miles traveled (VMT) in California, consumer price index, etc., details of which are provided in subsequent sections.

\section{CALIFORNIA PAVEMENT CONSTRUCTION COST DATA}

Caltrans annually publishes a Contractor Cost Data Book, which summarizes the cost by item for highway construction projects. Caltrans also maintains the online contractor cost data through a publicly accessible website which is manually updated biweekly from the contractors' bid documents. $^{8}$ The cost data are available from 1993 to present by item, district, and bid rank. As of April 2019, 2,686 construction items were recorded and listed in the construction cost database. Additionally, a total of 2.5 million records were included in the contractor cost database.

In the present research, 116,000 records of the pavement-related item costs were imported into the local server database to develop cost estimate models for major pavement-related items. The records include material item description, unit, district, quantity, unit price, total item price, year, and contract number.

\section{MAJOR AND MINOR ITEMS FOR PAVEMENT MAINTENANCE AND REHABILITATION ACTIVITY}

Table 4 displays information on pavement- and non-pavement-related items priced by unit collected from nine different states, including major and minor items. This research focused on the major items related to pavement maintenance and rehabilitation projects in LCCA, such as concrete paving, asphalt overlay, aggregate base, and subbase. 
Table 4. Pavement- and Non-Pavement-Related Items in Highway Construction

\begin{tabular}{ll}
\hline \multicolumn{1}{c}{ Category } & \multicolumn{1}{c}{ Item Description } \\
\hline Major Items (Pavement-related) & $\begin{array}{l}\text { concrete paving, widening, shoulders, bituminous paving, widening shoulder, } \\
\text { aggregate base, subbase, surface patching, cold milling, hauling, traffic } \\
\text { control, seal coat, storm sewers, concrete structures, etc. } \\
\text { Major Items (Non-pavement-related) } \\
\text { cofferdams, concrete box culverts, piling, sweeping, structure removal, } \\
\text { hauling, earth excavation, borrow embankment, etc. }\end{array}$ \\
pavement marking, driveway pavement, bridge deck overlay, bridge \\
pinor Items (Non-pavement-related) \\
$\begin{array}{l}\text { approach pavement, etc. } \\
\text { lighting, traffic signals, signing, weed spraying, crack routing, landscaping, } \\
\text { pipe culverts, pipe underdrains and pipe drains, manholes, catch basins, } \\
\text { inlets, curb and gutter, sidewalk, electrical maintenance, reinforcing steel, } \\
\text { soil stabilization, anchors and tiebacks, fencing, railroad track construction, } \\
\text { bearing, deck grooving, etc. }\end{array}$ \\
\hline
\end{tabular}

In view of the information gathered from other states, the primary pavement materials for both rigid and flexible pavements used in calculation of the future maintenance and rehabilitation activities in Caltrans LCCA were identified and are listed in Table 5.

Table 5. List of Primary Pavement Items used in Future M\&R in LCCA

\begin{tabular}{lrrr}
\hline \multicolumn{1}{c}{ Pavement Item Description } & Unit & Number of Projects & Data Period \\
\hline Roadway Excavation & CY & 4,151 & $1999-2018$ \\
Class 1 Aggregate Subbase (C1AS) & CY & 29 & $1999-2018$ \\
Class 2 Aggregate Subbase (C2AS) & CY & 210 & $1999-2018$ \\
Class 2 Aggregate Base (C2AB) & CY & 800 & $2012-2018$ \\
Class 3 Aggregate Base (C3AB) & CY & 160 & $2012-2018$ \\
Hot Mix Asphalt, Type A (HMA-A) & Ton & 2,415 & $2008-2018$ \\
Hot Mix Asphalt, Open Graded (HMA-O) & Ton & 57 & $2015-2018$ \\
Rubberized Hot Mix Asphalt, Gap Graded (RHMA) & Ton & 681 & $2008-2018$ \\
Rubberized Hot Mix Asphalt, Open Graded (RHMA-O) & Ton & 66 & $2015-2018$ \\
Jointed Plain Concrete Pavement (JPCP) & CY & 200 & $2009-2019$ \\
Jointed Plain Concrete Pavement, Rapid Setting Concrete (JPCP-RSC) & CY & 89 & $2014-2018$ \\
Lean Concrete Base (LCB) & CY & 501 & $1999-2018$ \\
Lean Concrete Base, Rapid Setting Concrete (LCB-RSC) & CY & 105 & $2013-2018$ \\
\hline
\end{tabular}

As an example of changes of material unit prices over time, Figure 1 shows the average unit price change of jointed plain concrete pavement (JPCP) by project size in each district over time. The discussion about determining the project sizes is described in the later section (Chapter IV). The unit price of the primary pavement items listed in Table 5 are shown by project size in Appendix $\mathrm{C}$. 


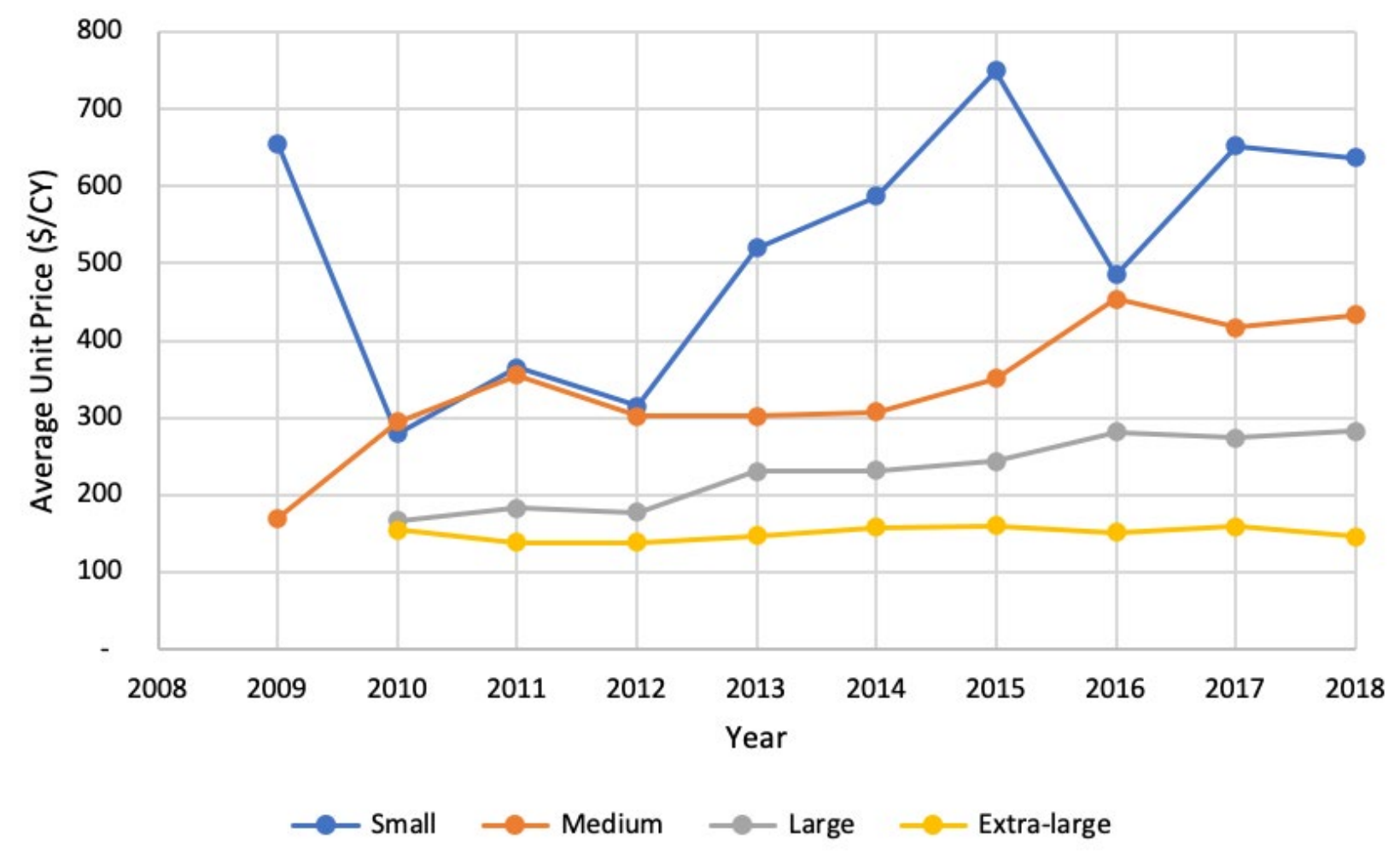

Figure 1. Unit Price Changes of Jointed Plain Concrete Pavement (JPCP) by Project Size in 2009-2018

\section{SOCIO-ECONOMIC PARAMETERS}

Three major components of pavement-related materials are asphalt, concrete, and aggregates; the unit prices of the materials are associated with socio-economic parameters that are directly linked with material production and raw materials. For example, consider crude oil price for asphalt binders and industry cement price for cement mix. Transportation and labor costs are related to consumer price index, inflation rate, and gasoline/diesel price. Considering this information and in view of the literature, data related to the following selected socio-economic parameters were collected from multiple sources for review in this research.

- Gasoline/diesel price

- Population

- Crude oil price

- Annual construction budget

- Vehicle registration and vehicle miles traveled

- Consumer price index 
- State expenditure in transportation

- Inflation rate, industry cement price, etc.

\section{State Annual Gas Prices}

The state annual gas price represents the cost of gasoline per gallon for each type of fuel grade, including diesel cost, which was obtained from the U.S. Energy Information Administration indexed by state. ${ }^{14}$ The dataset contained monthly and annual gas prices, both of which show similar trends. As shown in Table 6 and Figure 2, from 1994 until 2002, gas prices were generally flat with little variation, after which the cost gradually continued to increase until 2008. From 2008 to 2009, the cost dropped, corresponding with the 2008 recession. From 2009 to 2012, the price continued to increase, and from 2012 to 2016, it dropped back to values equivalent to the lowest price seen during the 2008 recession. From 2016 to present, the prices have resumed an almost linear increase. Both the monthly and annual gas prices display minimal variation among the different grades of fuel and are almost equal in terms of behavior across time. Changes of gas prices influence on vehicle miles traveled, pavement damages, and material' unit prices directly or indireclty. 


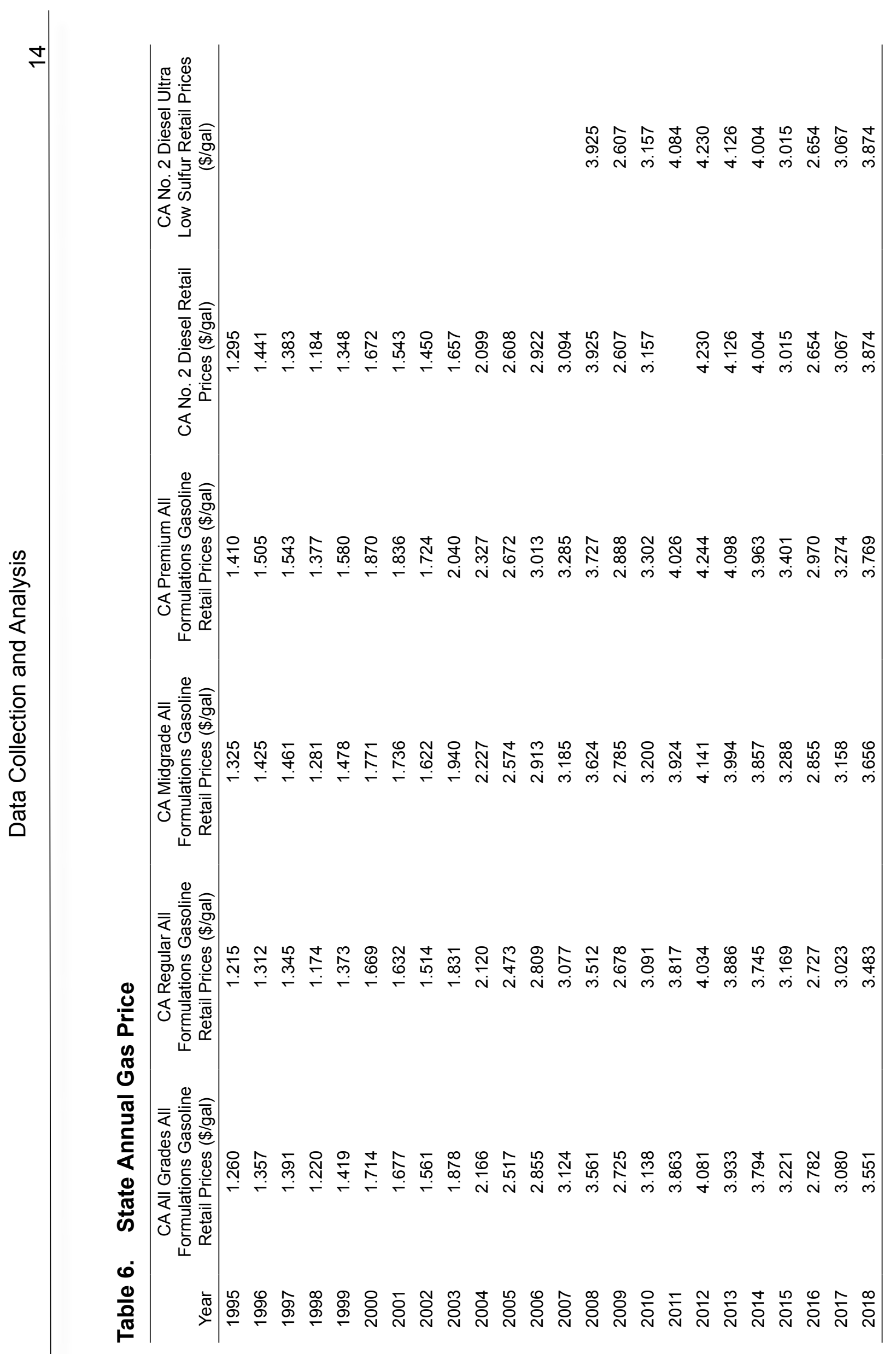




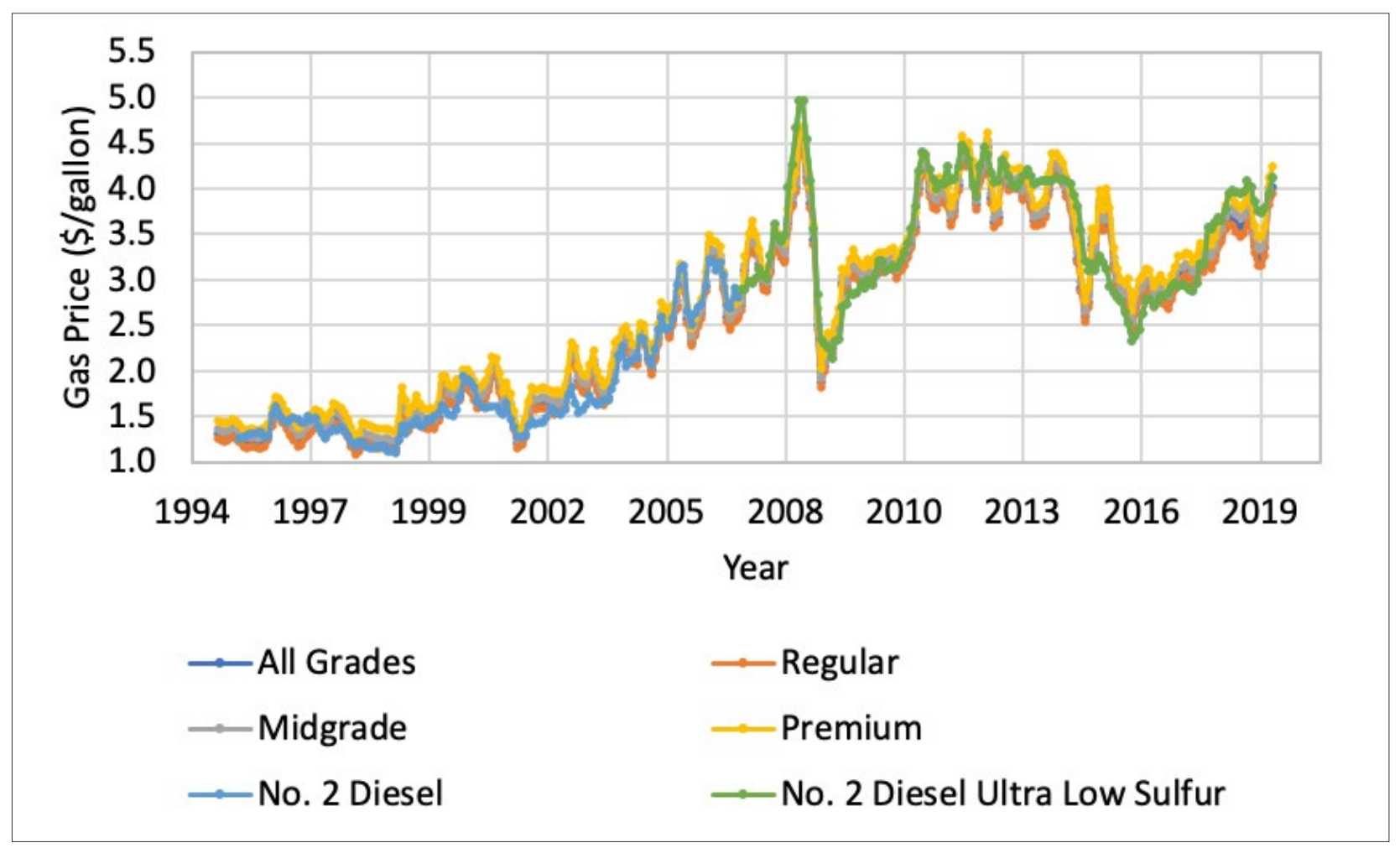

Figure 2. California Gas Prices

\section{Crude Oil Prices}

Table 7 and Figure 3 show the yearly average national crude oil prices (both imported and domestic sources) in the United States from 1986 to 2019. The data were retrieved from the United States Energy Information Administration, Independent Statistics and Analytics. ${ }^{14}$ General trends display an almost constant price for crude oil from 1986 to 1999 with an approximate spot price of $\$ 20$ per barrel, whereas from 2000 to 2008, the spot price continually increased linearly to $\$ 100$. From 2008 to 2009, the price dropped to the 2006 value of $\$ 61$, showcasing the effects of the 2008 recession. From 2009 to 2011 , the price increased again nearly to 2008 values and remained relatively constant from 2011 to 2014 . Afterwards, the price dropped to a 2005 value of approximately $\$ 50$ per barrel by 2015 . From 2015 to present, the price has increased linearly. 
Table 7. National Crude Oil Price

\begin{tabular}{|c|c|c|}
\hline Year & National Average (\$/barrel) Crude Oil Prices & $\%$ Change \\
\hline 1986 & 15.04 & \\
\hline 1987 & 19.17 & 4.13 \\
\hline 1988 & 15.98 & -3.19 \\
\hline 1989 & 19.64 & 3.66 \\
\hline 1990 & 24.47 & 4.83 \\
\hline 1991 & 21.5 & -2.97 \\
\hline 1992 & 20.56 & -0.94 \\
\hline 1993 & 18.45 & -2.11 \\
\hline 1994 & 17.19 & -1.26 \\
\hline 1995 & 18.44 & 1.25 \\
\hline 1996 & 22.11 & 3.67 \\
\hline 1997 & 20.61 & -1.50 \\
\hline 1998 & 14.45 & -6.16 \\
\hline 1999 & 19.26 & 4.81 \\
\hline 2000 & 30.3 & 11.04 \\
\hline 2001 & 25.95 & -4.35 \\
\hline 2002 & 26.12 & 0.17 \\
\hline 2003 & 31.12 & 5.00 \\
\hline 2004 & 41.44 & 10.32 \\
\hline 2005 & 56.49 & 15.05 \\
\hline 2006 & 66.02 & 9.53 \\
\hline 2007 & 72.32 & 6.30 \\
\hline 2008 & 99.57 & 27.25 \\
\hline 2009 & 61.65 & -37.92 \\
\hline 2010 & 79.4 & 17.75 \\
\hline 2011 & 94.87 & 15.47 \\
\hline 2012 & 94.11 & -0.76 \\
\hline 2013 & 97.91 & 3.80 \\
\hline 2014 & 93.26 & -4.65 \\
\hline 2015 & 48.69 & -44.57 \\
\hline 2016 & 43.14 & -5.55 \\
\hline 2017 & 50.88 & 7.74 \\
\hline 2018 & 64.94 & 14.06 \\
\hline
\end{tabular}




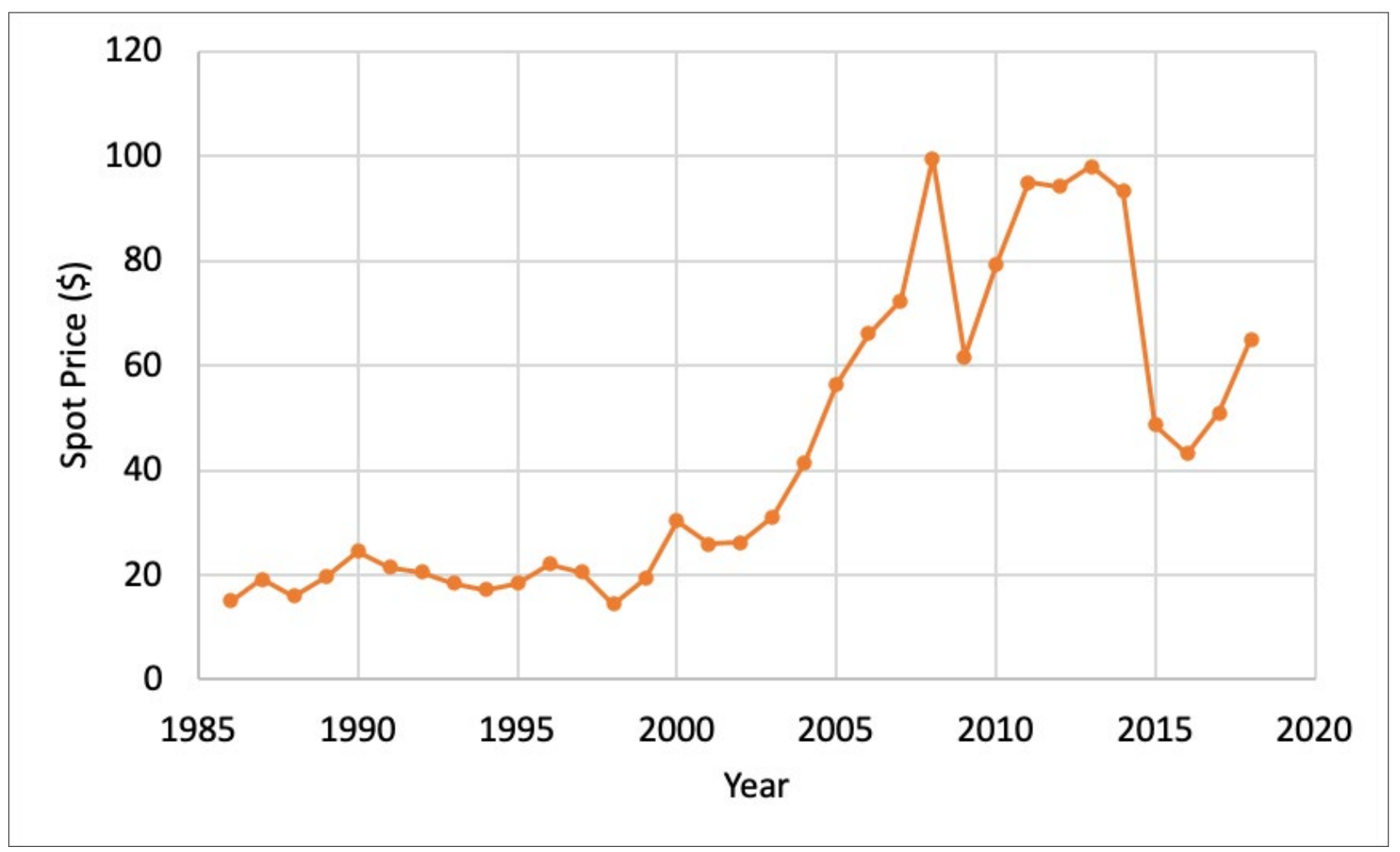

Figure 3. Annual National Crude Oil Prices

\section{California Vehicle Miles Traveled (VMT)}

The value of California Vehicle Miles Travelled (VMT) represents the cumulative total amount of vehicle miles travelled throughout the State of California's roadway networks, including minor and major roadways, arterials, and connectors. The values serve as a representative behavioral indicator of all vehicle miles travelled, including by all public/commercial and privately-owned vehicles. The data were retrieved from the Bureau of Transportation Statistics (BTS) of U.S. Department of Transportation. ${ }^{15}$ Additionally, data were also sourced from the Federal Highway Administration, specifically the Office of Highway Policy Information. BTS's database only has VMT data up until 2013, but both data sources had identical values for the VMT and this combination was deemed sufficient to use as data for the analysis. Trends in the data, as illustrated in Table 8, show a continual growth from 1997 until 2004, where the VMT stagnated up through 2008. Similarly, from 2008 until 2011, the VMT gradually decreased corresponding with the 2008 recession. After 2011, the CA VMT almost linearly increases until the present day. 
Table 8. California Vehicles Miles Travelled (VMT)

\begin{tabular}{|c|c|c|c|c|}
\hline Year & CA VMT (Millions) & CA VMT Per Capita & VMT Change & Per Capita Change \\
\hline 1997 & 279,096 & 8,591 & NA & NA \\
\hline 1998 & 290,630 & 8,810 & 11,534 & 219 \\
\hline 1999 & 300,066 & 9,053 & 9,436 & 243 \\
\hline 2000 & 306,649 & 9,018 & 6,583 & -35 \\
\hline 2001 & NA & NA & NA & NA \\
\hline 2002 & 320,942 & 9,179 & NA & NA \\
\hline 2003 & 323,592 & 9,165 & 2,650 & -14 \\
\hline 2004 & 328,917 & 9,250 & 5,325 & 85 \\
\hline 2005 & 329,267 & 9,199 & 350 & -51 \\
\hline 2006 & 327,478 & 9,102 & $-1,789$ & -97 \\
\hline 2007 & 328,312 & 9,057 & 834 & -45 \\
\hline 2008 & 327,286 & 8,904 & $-1,026$ & -153 \\
\hline 2009 & 324,486 & 8,779 & $-2,800$ & -125 \\
\hline 2010 & 322,849 & 8,647 & $-1,637$ & -132 \\
\hline 2011 & 320,784 & 8,512 & $-2,065$ & -135 \\
\hline 2012 & 326,272 & 8,577 & 5,488 & 65 \\
\hline 2013 & 329,534 & 8,576 & 3,262 & -1 \\
\hline 2014 & 332,857 & 8,588 & 3,323 & 12 \\
\hline 2015 & 335,539 & 8,587 & 2,682 & -2 \\
\hline 2016 & 340,115 & 8,648 & 4,576 & 61 \\
\hline 2017 & 343,862 & 8,681 & 3,747 & 33 \\
\hline
\end{tabular}

\section{California Vehicle Registration}

The California Vehicle Registration metric represents the cumulative total number of vehicles actively registered in the State of California, including both private/commercial and public vehicles. Data range from 1997 to 2017. The values serve to represent the economic trends within California and the number of vehicles operating on California's roadway network. Data were retrieved from the U.S. Department of Transportation's Federal Highway Administration. ${ }^{15}$ General trends as presented in Table 9 show a gradual increase in vehicle registration numbers from 1997 till 2006. There is a visible decrease in both truck (private/commercial) as well as auto (private/commercial) registrations from 2009 to 2013, corresponding with the 2008 recession. Since 2013, these numbers have steadily increased (nearly linearly), although they have not matched the total number of vehicles registered in 2007. 


\section{Table 9. California Vehicle Registration}

\begin{tabular}{lc}
\hline Year & Total Vehicle Registration (Private, Public, and Commercial) \\
\hline 1997 & $24,944,976$ \\
1998 & $25,600,250$ \\
1999 & $26,362,468$ \\
2000 & $27,697,923$ \\
2001 & $28,780,056$ \\
2002 & $29,618,605$ \\
2003 & $30,248,069$ \\
2004 & $31,399,596$ \\
2005 & $32,487,477$ \\
2006 & $33,182,058$ \\
2007 & $33,935,386$ \\
2008 & $33,483,061$ \\
2009 & $34,433,206$ \\
2010 & $31,014,128$ \\
2011 & $29,176,697$ \\
2012 & $27,702,150$ \\
2013 & $28,074,977$ \\
2014 & $28,686,646$ \\
2015 & $29,424,012$ \\
2016 & $30,221,033$ \\
2017 & $30,795,141$ \\
2018 & $31,022,328$ \\
\hline & \\
\hline
\end{tabular}

\section{Population}

The population dataset represents the State of California's total population estimates from 1970 to 2018. The numbers serve as representative values of the population based on local county estimates, including the once per decade census counts. Data were retrieved from the State of California's Department of Finance website and included demographic data and forecasting estimates. ${ }^{16}$ Table 10 and Figure 4 show the general trends for the total population estimate in the State of California, revealing steady linear growth from 1970 to present. However, a very slight tapering of the rate of change can be seen relative to the entire data trend from 1970 to 2018 . 
Table 10. California Population Growth

\begin{tabular}{lccc}
\hline Year & California Population & Year & California Population \\
\hline 1970 & $20,039,000$ & 1995 & $31,711,849$ \\
1971 & $20,346,000$ & 1996 & $31,962,949$ \\
1972 & $20,585,000$ & 1997 & $32,452,789$ \\
1973 & $20,869,000$ & 1998 & $32,862,965$ \\
1974 & $21,174,000$ & 1999 & $33,418,578$ \\
1975 & $21,538,000$ & 2000 & $34,095,209$ \\
1976 & $21,936,000$ & 2001 & $34,512,742$ \\
1977 & $22,352,000$ & 2002 & $34,938,290$ \\
1978 & $22,839,000$ & 2003 & $35,388,928$ \\
1979 & $23,257,000$ & 2004 & $35,752,765$ \\
1980 & $23,782,000$ & 2005 & $35,985,582$ \\
1981 & $24,278,000$ & 2006 & $36,246,822$ \\
1982 & $24,805,000$ & 2007 & $36,552,529$ \\
1983 & $25,337,000$ & 2008 & $36,856,222$ \\
1984 & $25,816,000$ & 2009 & $37,077,204$ \\
1985 & $26,402,000$ & 2010 & $37,318,481$ \\
1986 & $27,052,000$ & 2011 & $37,678,534$ \\
1987 & $27,717,000$ & 2012 & $38,045,271$ \\
1988 & $28,393,000$ & 2013 & $38,425,695$ \\
1989 & $29,142,000$ & 2014 & $38,756,940$ \\
1990 & $29,828,496$ & 2015 & $39,076,128$ \\
1991 & $30,458,613$ & 2016 & $39,328,337$ \\
1992 & $30,987,384$ & 2017 & $39,610,556$ \\
1993 & $31,314,189$ & 2018 & $39,825,181$ \\
1994 & $31,523,690$ & & \\
\hline
\end{tabular}

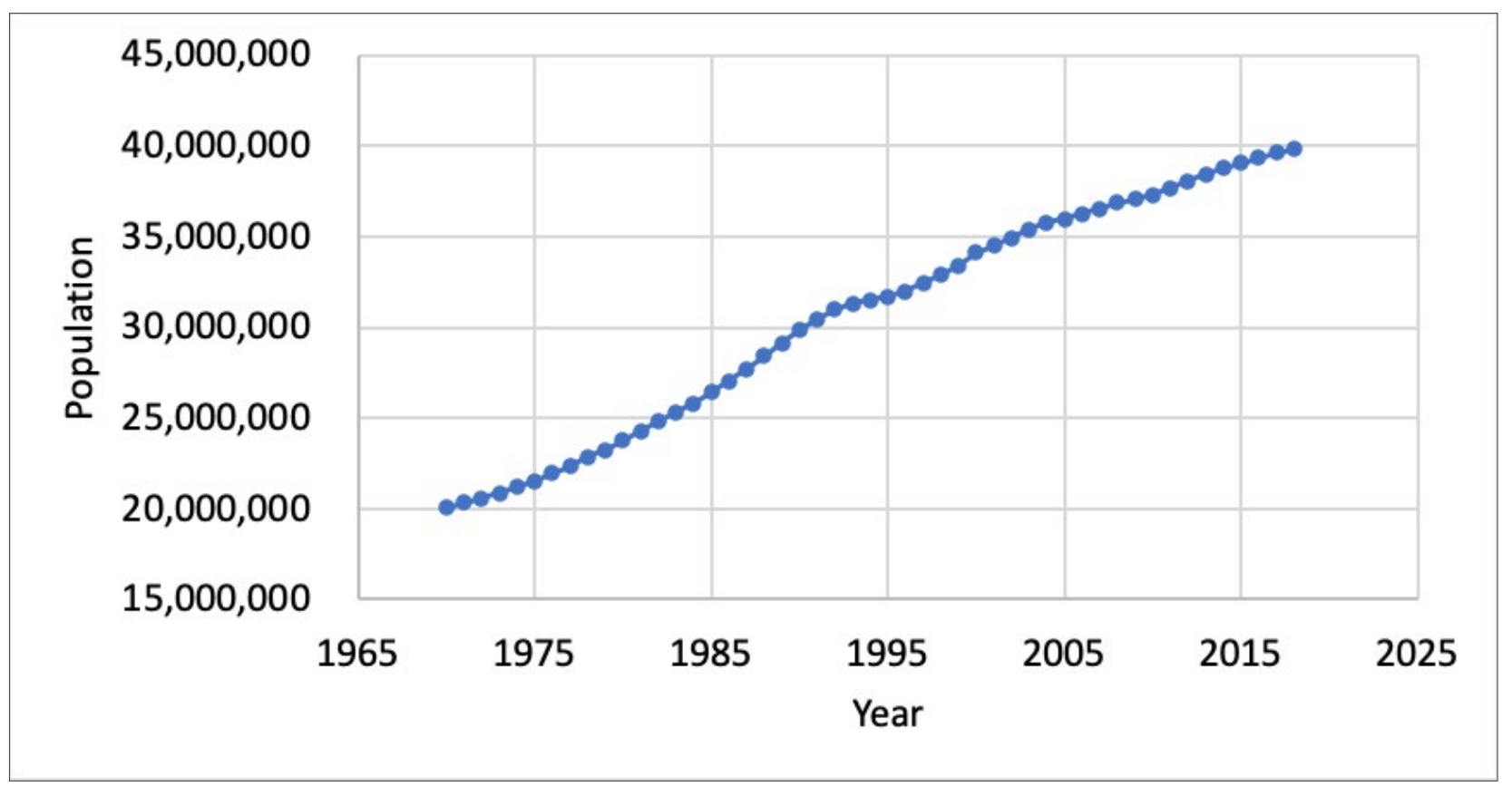

Figure 4. California Population Growth (1970-2018) 


\section{Inflation}

The inflation dataset showcases the inflation specific to the State of California from 1955 to 2018. The dataset is separated into three sections based on California Gross Domestic Product (GDP), Personal Consumer Index (CPI), and State and Local Purchases Index. The values serve as a representative of behavior of the State of California's economic growth and general trends across each individual year. The data were obtained from the State of California's Department of Finance. ${ }^{17}$ Table 11 shows the GDP index, personal consumption expenditures index, and state and local purchase index in California from 1980 to 2018. Table 11 shows an almost linear growth in inflation from 1980 to 2018. The only visible discrepancy is a slight stagnation of growth immediately after 2008, indicative of the 2008 economic recession. 
Table 11. Changes of Inflation Rates

\begin{tabular}{|c|c|c|c|}
\hline Year & CA GDP Index & CA Personal Consumption Expenditures Index & CA State and Local Purchases Index \\
\hline 1980 & 42.27 & 41.26 & 30.08 \\
\hline 1981 & 46.27 & 44.96 & 33.23 \\
\hline 1982 & 49.13 & 47.46 & 35.40 \\
\hline 1983 & 51.06 & 49.47 & 36.96 \\
\hline 1984 & 52.90 & 51.34 & 38.54 \\
\hline 1985 & 54.57 & 53.13 & 40.11 \\
\hline 1986 & 55.67 & 54.29 & 41.27 \\
\hline 1987 & 57.05 & 55.96 & 43.20 \\
\hline 1988 & 59.06 & 58.15 & 44.64 \\
\hline 1989 & 61.37 & 60.69 & 46.75 \\
\hline 1990 & 63.67 & 63.36 & 49.15 \\
\hline 1991 & 65.83 & 65.47 & 50.95 \\
\hline 1992 & 67.33 & 67.22 & 52.69 \\
\hline 1993 & 68.92 & 68.89 & 54.00 \\
\hline 1994 & 70.39 & 70.33 & 55.39 \\
\hline 1995 & 71.87 & 71.81 & 56.87 \\
\hline 1996 & 73.18 & 73.35 & 58.18 \\
\hline 1997 & 74.45 & 74.62 & 59.47 \\
\hline 1998 & 75.28 & 75.22 & 60.63 \\
\hline 1999 & 76.37 & 76.34 & 63.01 \\
\hline 2000 & 78.08 & 78.24 & 66.03 \\
\hline 2001 & 79.79 & 79.74 & 68.28 \\
\hline 2002 & 81.05 & 80.79 & 69.82 \\
\hline 2003 & 82.56 & 82.36 & 72.05 \\
\hline 2004 & 84.78 & 84.41 & 75.37 \\
\hline 2005 & 87.42 & 86.81 & 79.61 \\
\hline 2006 & 90.07 & 89.17 & 83.62 \\
\hline 2007 & 92.49 & 91.44 & 88.13 \\
\hline 2008 & 94.29 & 94.18 & 92.56 \\
\hline 2009 & 95.00 & 94.09 & 92.05 \\
\hline 2010 & 96.11 & 95.71 & 94.67 \\
\hline 2011 & 98.12 & 98.13 & 97.74 \\
\hline 2012 & 100.00 & 100.00 & 100.00 \\
\hline 2013 & 101.76 & 101.35 & 103.28 \\
\hline 2014 & 103.68 & 102.87 & 105.67 \\
\hline 2015 & 104.79 & 103.13 & 105.75 \\
\hline 2016 & 105.94 & 104.24 & 105.97 \\
\hline 2017 & 107.95 & 106.07 & 109.16 \\
\hline 2018 & 110.38 & 108.23 & 113.01 \\
\hline
\end{tabular}




\section{State Budget Transportation Expenditure}

The California Budget Transportation Expenditure represents the State of California's budget allocated towards transportation-related projects and agencies. The data selected are specific only to California-funded projects and exclude all federally funded or partially funded projects. Table 12 shows the California expenditures in transportation from 1989 to 2018 The data were obtained from the California's Legislative Analyst's Office, Nonpartisan Fiscal and Policy Advisor. ${ }^{18}$ General trend in Table 12 shows a significant amount of unpredictability in funding which fluctuates greatly across each year. Funding prior to 1990 was substantially low, with a gradual increase in funding from 1990 to 2000. From 2000 onward, the funding amounts fluctuate significantly, with the year of 2012 resulting in negative funding of 100 million. Since 2012, funding has gradually continued to increase.

Table 12. California Budget Transportation Expenditure

\begin{tabular}{lc}
\hline Fiscal Year & State Expenditure Transportation \\
\hline $1989-1990$ & $\$ 12,460,000$ \\
$1990-1991$ & $\$ 5,978,000$ \\
$1991-1992$ & $\$ 36,270,000$ \\
$1992-1993$ & $\$ 67,751,000$ \\
$1993-1994$ & $\$ 93,850,000$ \\
$1994-1995$ & $\$ 149,903,000$ \\
$1995-1996$ & $\$ 173,078,000$ \\
$1996-1997$ & $\$ 199,170,000$ \\
$1997-1998$ & $\$ 222,035,000$ \\
$1998-1999$ & $\$ 259,744,000$ \\
$1999-2000$ & $\$ 288,993,000$ \\
$2000-2001$ & $\$ 360,420,000$ \\
$2001-2002$ & $\$ 255,717,000$ \\
$2002-2003$ & $\$ 189,737,000$ \\
$2003-2004$ & $\$ 193,084,000$ \\
$2004-2005$ & $\$ 347,468,000$ \\
$2005-2006$ & $\$ 340,382,000$ \\
$2006-2007$ & $\$ 349,855,000$ \\
$2007-2008$ & $\$ 1,039,000$ \\
$2008-2009$ & $\$ 232,433,000$ \\
$2009-2010$ & $\$ 365,332,000$ \\
$2010-2011$ & $\$ 59,045,000$ \\
$2011-2012$ & $\$ 131,470,000$ \\
$2012-2013$ & $-\$ 114,165,000$ \\
$2013-2014$ & $\$ 115,255,000$ \\
$2014-2015$ & $\$ 178,929,000$ \\
$2015-2016$ & $\$ 224,626,000$ \\
$2016-2017$ & $\$ 241,488,000$ \\
$2017-2018$ & \\
& \\
\hline 2000
\end{tabular}




\section{California Minimum Wage}

The California minimum wage dataset represents the State's minimum wage from 1916 to 2018. The values serve as a representative of the labor cost throughout California for each given year. The dataset does not represent prevailing minimum wage, instead only displaying the state-mandated minimum wage. The data were obtained from the State of California's Department of Industrial Relations..$^{19}$ The general trend in Table 13 shows an almost exponential growth in minimum wage values across each year.

Table 13. California Minimum Wage

\begin{tabular}{ccccc}
\hline $\begin{array}{c}\text { Effective Date } \\
(\mathrm{mm} / \mathrm{dd} / \mathrm{yyyy})\end{array}$ & $\begin{array}{c}\text { New } \\
\text { Minimum Wage }\end{array}$ & $\begin{array}{c}\text { Old } \\
\text { Minimum Wage }\end{array}$ & $\begin{array}{c}\text { Amount of } \\
\text { Wage Increase }\end{array}$ & $\begin{array}{c}\text { Percent } \\
\text { Increase }\end{array}$ \\
\hline $01 / 01 / 1980$ & $\$ 3.10$ & $\$ 2.90$ & $\$ 0.20$ & 6.90 \\
$01 / 01 / 1981$ & $\$ 3.35$ & $\$ 3.10$ & $\$ 0.25$ & 8.06 \\
$07 / 01 / 1988$ & $\$ 4.25$ & $\$ 3.35$ & $\$ 0.90$ & 26.87 \\
$10 / 01 / 1996$ & $\$ 4.75$ & $\$ 4.25$ & $\$ 0.50$ & 11.76 \\
$03 / 01 / 1997$ & $\$ 5.00$ & $\$ 4.75$ & $\$ 0.25$ & 5.26 \\
$09 / 01 / 1997$ & $\$ 5.15$ & $\$ 5.00$ & $\$ 0.15$ & 3.00 \\
$03 / 01 / 1998$ & $\$ 5.75$ & $\$ 5.15$ & $\$ 0.60$ & 11.65 \\
$01 / 01 / 2001$ & $\$ 6.25$ & $\$ 5.75$ & $\$ 0.50$ & 8.70 \\
$01 / 01 / 2002$ & $\$ 6.75$ & $\$ 6.25$ & $\$ 0.50$ & 8.00 \\
$01 / 01 / 2007$ & $\$ 7.50$ & $\$ 6.75$ & $\$ 0.75$ & 11.10 \\
$01 / 01 / 2008$ & $\$ 8.00$ & $\$ 7.50$ & $\$ 0.50$ & 6.70 \\
$07 / 01 / 2014$ & $\$ 9.00$ & $\$ 8.00$ & $\$ 1.00$ & 12.50 \\
$01 / 01 / 2016$ & $\$ 10.00$ & $\$ 9.00$ & $\$ 1.00$ & 11.10 \\
$01 / 01 / 2017$ & $\$ 10.50$ & $\$ 10.00$ & $\$ 0.50$ & 5.00 \\
$01 / 01 / 2018$ & $\$ 11.00$ & $\$ 10.50$ & $\$ 0.50$ & 4.88 \\
\hline
\end{tabular}




\section{MODEL DEVELOPMENT}

Pavement cost data obtained from Caltrans resources and data on various socio-economic parameters as described in the previous chapter were incorporated into a local database for subsequent analysis. Several steps were undertaken in the analysis of data to develop a statistical model for predicting pavement material unit price, details of which are presented in the subsequent section.

\section{VARIATION IN PAVEMENT MATERIAL UNIT PRICE BY GEOGRAPHICAL LOCATION}

To explore any variation in the materials' unit prices by geographic location, the research team selected the two most important pavement materials: Joint Plain Concrete Pavement (JPCP) for rigid pavement and hot mix asphalt Type A (HMA-A) for flexible pavement. JPCP and HMA-A are the most commonly used pavement materials in California highway construction. JPCP was used in 200 projects from 2009-2019, and HMA-A was used in 2,415 projects from 2008-2018. Both materials were used in California highway construction before 2008, but it was not possible to match the material items before 2008, since these material items' codes were changed in the Caltrans construction cost database system in 2008.

The unit price of JPCP was analyzed for various districts in California using ANOVA. The results of that analysis are presented in Table 14. The null hypothesis was that the unit price of JPCP is similar in different districts and any differences are not statistically significant by geographic location. The ANOVA results show a P-value of 0.596 , which indicates that the null hypothesis cannot be rejected; hence there is no statistically significant variation in the unit price of JPCP by geographic location (districts) in California. Similarly, the ANOVA result for HMA-A data shows a P-value of 0.124 , thus confirming no statistically significant variation in unit price of HMA-A by geographic location (districts) in California.

Caltrans Highway Design Manual (HDM) contains information on pavement material selection and cross-section design by climate region. Caltrans' pavement climate region map defines nine climate regions in the California highway network according to the climate conditions and locations (North Coast, Central Coast, Inland Valley, Low Mountain, High Mountain, Desert, High Desert, South Coast, and South Mountain). ${ }^{6}$ The unit price data for JPCP and HMA-A were analyzed by climate region to explore any differences in price. The null hypothesis was that JPCP and HMA-A cost are similar with no statistically significant differences by climate region. The ANOVA test result as presented in Table 14 shows a P-value of 0.176 for JPCP, which means the null hypothesis cannot be rejected; hence there is no statistically significant variation in the unit price of JPCP by climate region in California. Similarly, the ANOVA result listed in Table 14 for HMA-A data shows a P-value of 0.158 , thus confirming no statistically significant variation in the unit price of HMA-A by climate region in California.

Given the abovementioned ANOVA test results, it can be concluded that there is no statistically significant variation in the unit price of JPCP and HMA-A by geographic location and climate region in California. Therefore, the variables were not separated by these factors for use in the development of the statistical models. 
Table 14. ANOVA Test Results of District and Climate variables for JPCP and HMA in 2018

\begin{tabular}{ccrrrrc}
\hline Variable & Type & Df & Sum Sq. & Mean Sq. & F-value & P-value \\
\hline District & JPCP & 7 & 425,567 & 60,795 & 0.801 & 0.596 \\
District & HMA-A & 11 & $2,817,603$ & 256,146 & 1.517 & 0.124 \\
Climate & JPCP & 5 & 541,890 & 108,378 & 1.701 & 0.176 \\
Climate & HMA-A & 7 & $1,815,015$ & 259,288 & 1.526 & 0.158 \\
\hline
\end{tabular}

\section{CORRELATION IN SOCIO-ECONOMIC VARIABLES}

In order to select the most critical socio-economic parameters as described in the previous chapter, the research team conducted a correlation analysis amongst the socio-economic variables. According to the correlation analysis results as presented in Table 15, crude oil price showed a strong correlation with gasoline and diesel price, and so the crude oil price variable was selected to represent gasoline prices and diesel prices in this research.

The California population showed a strong correlation with three parameters: vehicle miles traveled, consumer price index (CPI), and minimum wage. Therefore, the California population variable was selected and the other variables were dropped from subsequent analysis.

Two parameters, state expenditure in transportation and total vehicle registration, showed less correlation with other variables and thus were considered separately as the independent variables in this research.

In summary, four variables - crude oil price, population, state expenditure in transportation, and annual vehicle registration-were selected as the independent variables to represent corresponding socio-economic parameters to develop the statistical models in this research.

Table 15. Correlation Analysis Results for the Socio-Economic Parameters

\begin{tabular}{lccccccccc}
\hline \multicolumn{1}{c}{ Variable } & Gasoline & Diesel & Crude Oil & Population & Expenditure & Total Vehicle & VMT & CPI & Wage \\
\hline Gasoline & 1.00 & 0.99 & 0.93 & 0.88 & -0.47 & -0.66 & 0.69 & 0.89 & 0.75 \\
Diesel & 0.99 & 1.00 & 0.94 & 0.85 & -0.46 & -0.54 & 0.66 & 0.86 & 0.71 \\
Crude Oil & 0.93 & 0.94 & 1.00 & 0.76 & -0.04 & -0.25 & 0.53 & 0.78 & 0.58 \\
Population & 0.88 & 0.85 & 0.76 & 1.00 & 0.45 & -0.54 & 0.90 & 0.99 & 0.94 \\
Expenditure & -0.47 & -0.46 & -0.04 & 0.45 & 1.00 & 0.53 & -0.17 & 0.37 & -0.09 \\
Total Vehicles & -0.66 & -0.54 & -0.24 & -0.54 & 0.53 & 1.00 & -0.08 & -0.44 & -0.12 \\
VMT & 0.69 & 0.66 & 0.53 & 0.90 & -0.18 & -0.09 & 1.00 & 0.87 & 0.87 \\
CPI & 0.89 & 0.86 & 0.78 & 0.99 & 0.38 & -0.44 & 0.87 & 1.00 & 0.97 \\
Wage & 0.75 & 0.71 & 0.58 & 0.94 & -0.09 & -0.12 & 0.87 & 0.97 & 1.00 \\
\hline
\end{tabular}




\section{TIME-SERIES ANALYSIS OF SOCIO-ECONOMIC VARIABLES}

In order to predict the future cost of each of the four selected socio-economic variables, time-series analysis was conducted for the next 50 years of the LCCA period from 2020 to 2069. The Autoregressive Integrated Moving Average (ARIMA) modeling approach was implemented using the $R$ programming language to develop the predictive model of each of the four socio-economic variables. Several ARIMA models were developed with varying modelling parameters, and the best model was selected by minimizing the Akaike Information Criteria (AIC) values. The ARIMA model for each variable calculated the coefficients of three regressive parameters and the coefficients of the moving average of point values for one, two, and three years to filter out a unique type of finite impulse value for certain year. The coefficients of the autoregressive 1,2, 3, the moving average 1,2,3, the log likelihood, and Akaike Information Criteria (AIC) values of the ARIMA model of each variable are shown in Table 14. The model with the lower AIC value has relatively better goodness of fit than the model with the light AIC value. The authors found the best model structure (the autoregressive and the moving average) having the lowest AIC value for each variable.

Using the ARIMA models, the future point values of each variable were predicted for a 50 year LCCA period starting from 2020. Figures 5 through 8 show the past values and the future predicted values of each socio-economic variable used in this research. Figures 5 through 8 also show a simple linear graph using past data extended into the future to show a predicted line for comparison purposes. For three variables, crude oil, vehicle registration, and state expenditure in transportation, the ARIMA models fit well and smoothen the sharp decreases of the values due to the U.S. economic recession in 2008 (population did not decrease during the recession). The simple linear graph does not reflect the trend possibly affected by the sudden variation due to the 2008 U.S. economic recession and showed a large gap between the past values and the future predicted values. In Figures 5 through 8 , the differences of the predicted values between the simple linear regression models and the ARIMA models become larger as the prediction moves to a further future.

The predicted values of each variable from 2020 to 2069 were populated from the corresponding ARIMA model and are presented in Appendix B. 

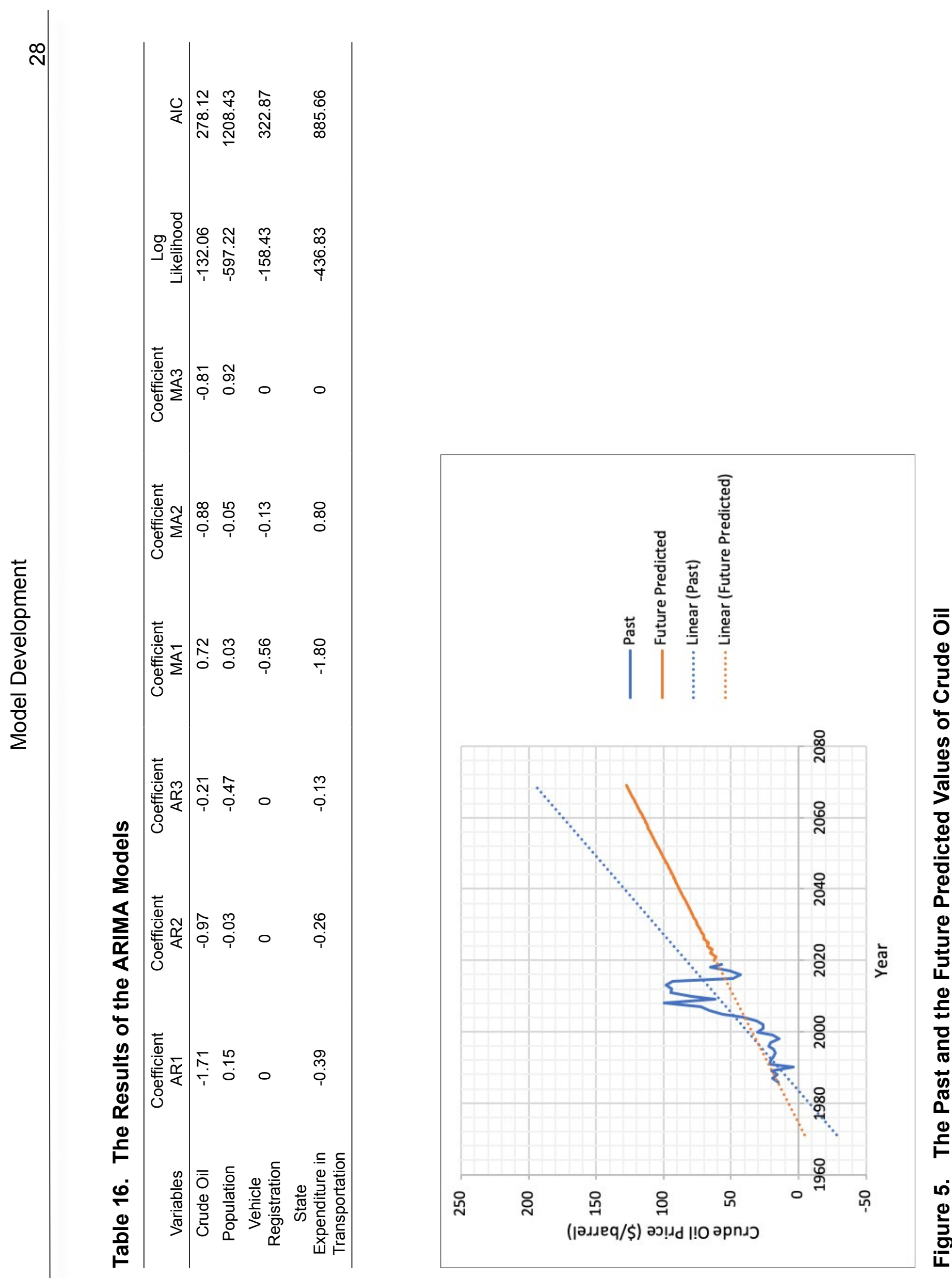


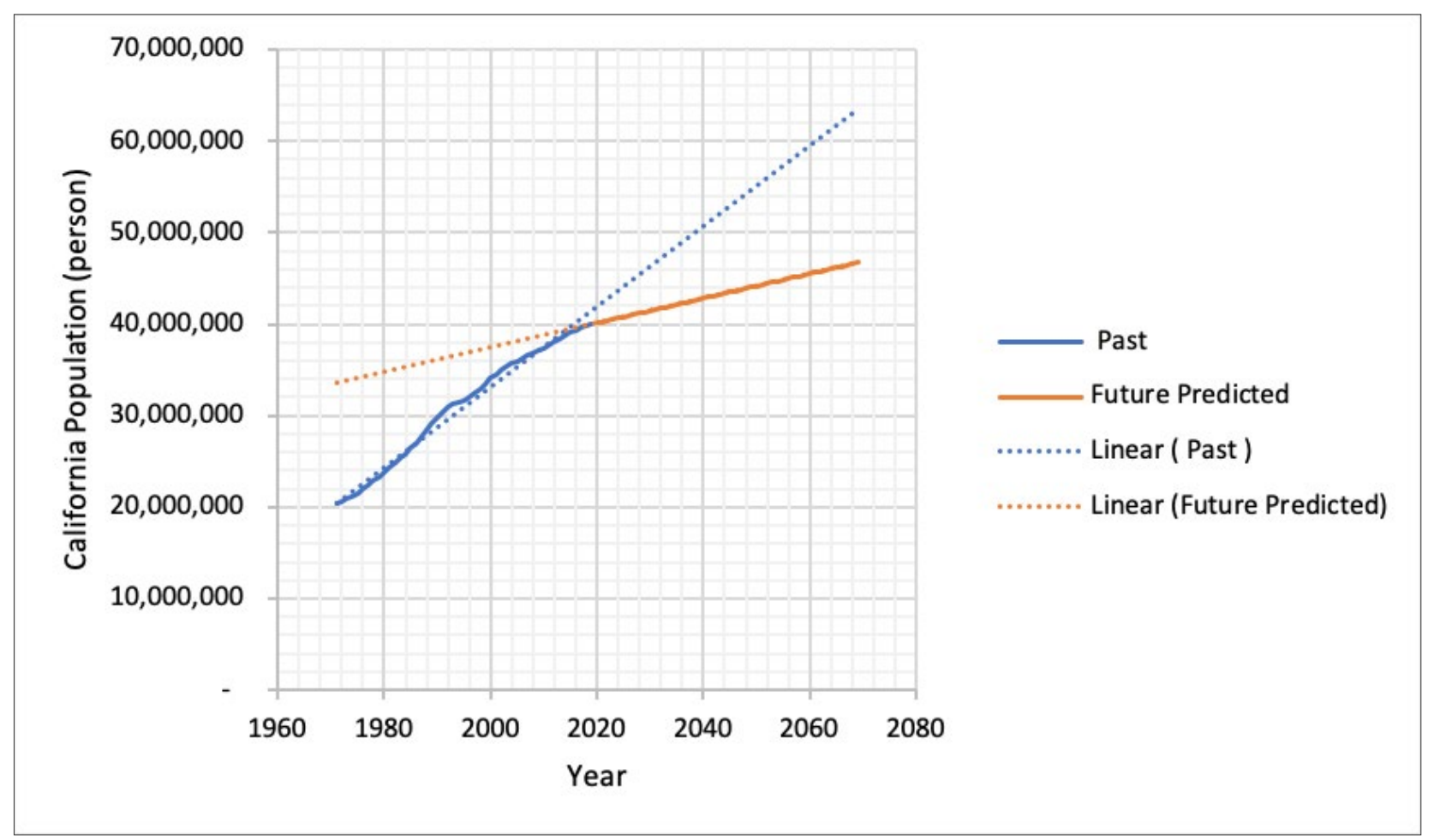

Figure 6. The Past and the Future Predicted Values of California Population

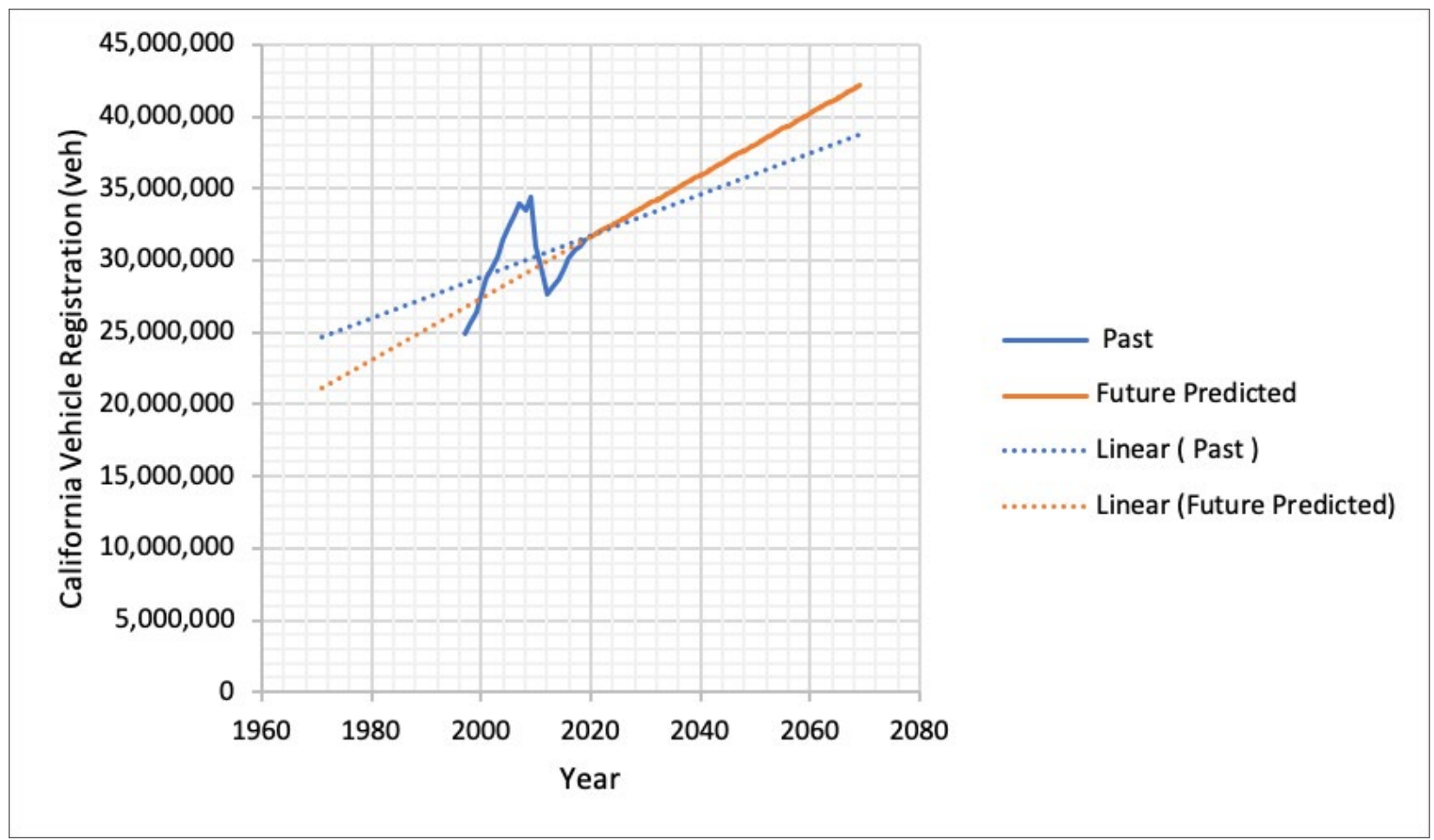

Figure 7. The Past and the Future Predicted Values of California Vehicle Registration 


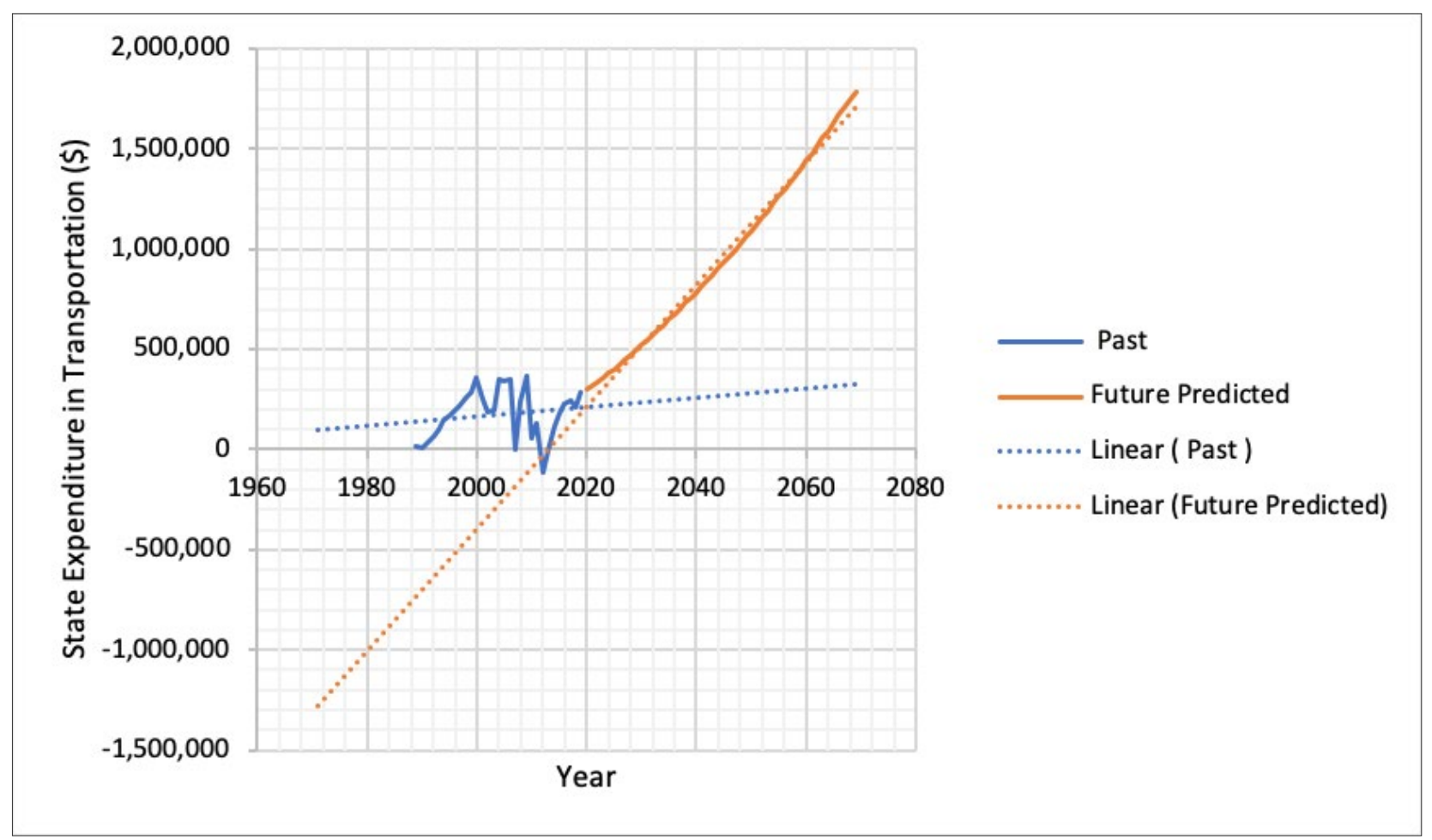

Figure 8. The Past and the Future Predicted Values of State Expenditure in Transportation

\section{MULTIPLE REGRESSION MODELS FOR PREDICTING PAVEMENT MATERIAL UNIT PRICE}

\section{Project Size}

In view of the information obtained from other states and the Caltrans database, pavement materials used in LCCA for future M\&R activities were identified and their unit price data were grouped by the quantities of the material. The unit prices show a large variability depending on the size of the project and quantity of material used. Small projects which require low quantity of a material generally show higher unit prices than larger projects. The research team classified the projects into four categories by project size based upon the amount of material quantities used (small, medium, large, and extra-large). The maximum quantities of material in small, medium, and large projects were determined by the $25^{\text {th }}, 50^{\text {th }}$, and $75^{\text {th }}$ percentiles, respectively. The projects with material quantity greater than the $75^{\text {th }}$ percentile value were classified as extra-large size projects. Table 17 shows the material type, unit, and the maximum quantity signifying the boundaries between small, medium, large, and extralarge projects (note that values exceeding the numbers in the large column correspond to extra-large projects). 
Table 17. Maximum Quantities by Project Size for the Primary Pavement Materials Used in LCCA

\begin{tabular}{lcrrr}
\hline \multicolumn{1}{c}{ Material Type } & Unit & Small & Medium & Large \\
\hline Roadway Excavation & CY & 300 & 1,500 & 9,000 \\
Class 2 Aggregate Subbase & CY & 300 & 1,500 & 8,500 \\
Class 2 Aggregate Base & CY & 200 & 1,000 & 3,000 \\
Class 3 Aggregate Base & CY & 100 & 500 & 2,000 \\
Hot Mix Asphalt (Type A) & Ton & 300 & 1,500 & 4,500 \\
Hot Mix Asphalt (Open Graded Friction Course) & Ton & 100 & 500 & 2,000 \\
Rubberized Hot Mix Asphalt (Gap Graded) & Ton & 2,500 & 7,500 & 16,000 \\
Rubberized Hot Mix Asphalt (Open Graded Friction Course) & Ton & 2,000 & 6,000 & 16,000 \\
Jointed Plain Concrete Pavement & CY & 200 & 1,500 & 12,000 \\
Jointed Plain Concrete Pavement (Rapid Setting) & CY & 200 & 500 & 1,500 \\
Lean Concrete Base & CY & 200 & 1,000 & 7,000 \\
Lean Concrete Base (Rapid Setting) & CY & 100 & 300 & 1,000 \\
\hline
\end{tabular}

To further investigate the impact of project size on materials' unit price, the average unit prices of the primary pavement materials used in the M\&R activities in 2018 were calculated by project size, as shown in Table 18. For example, the average unit price (\$637) of JPCP for the small project with an upper limit of 200 cubic yards was 4.4 times higher than the average unit price (\$146) for the extra-large projects in 2018 for the same material. Figure 9 shows the average unit prices of Joint Plain Concrete Pavement by project size from 2008 to 2018 . The average unit price for pavement materials varied widely (from $\$ 300$ to $\$ 750$ ) for small projects over the years, but the unit price remained relatively stable for all other project sizes with a slight increase over the years. 
Table 18. Average Unit Prices of the Primary Pavement Materials by Project Size in 2018

\begin{tabular}{lccccc}
\hline \multicolumn{1}{c}{ Material } & Unit & $\begin{array}{c}\text { Small } \\
\text { (no. of projects) }\end{array}$ & $\begin{array}{c}\text { Medium } \\
\text { (no. of projects) }\end{array}$ & $\begin{array}{c}\text { Large } \\
\text { (no. of projects) }\end{array}$ & $\begin{array}{c}\text { Extra-Large } \\
\text { (no. of projects) }\end{array}$ \\
\hline Roadway Excavation & CY & $\$ 267$ & $\$ 106$ & $\$ 60$ & $\$ 30$ \\
Class 2 Aggregate Subbase & CY & $(1,048)$ & $(979)$ & $(1,076)$ & $(1,048)$ \\
& & $\$ 163$ & $\$ 110$ & $\$ 51$ & $\$ 32$ \\
Class 2 Aggregate Base & CY & $\$ 358$ & $(51)$ & $(52)$ & $(52)$ \\
& & $(224)$ & $\$ 127$ & $\$ 95$ & $\$ 55$ \\
Class 3 Aggregate Base & CY & $\$ 248$ & $\$ 185$ & $(153)$ & $(204)$ \\
& & $(44)$ & $(46)$ & $\$ 88$ & $\$ 66$ \\
Hot Mix Asphalt (Type A) & Ton & $\$ 591$ & $\$ 232$ & $\$ 147$ & $(37)$ \\
& & $(662)$ & $(653)$ & $(513)$ & $\$ 104$ \\
Hot Mix Asphalt (Open Graded & Ton & $\$ 255$ & $\$ 179$ & $\$ 162$ & $\$ 109$ \\
Friction Course) & & $(10)$ & $(19)$ & $(14)$ & $(14)$ \\
Rubberized Hot Mix Asphalt (Gap & Ton & $\$ 210$ & $\$ 132$ & $\$ 118$ & $\$ 108$ \\
Graded) & & $(170)$ & $(183)$ & $(160)$ & $(167)$ \\
Rubberized Hot Mix Asphalt (Open & Ton & $\$ 160$ & $\$ 147$ & $\$ 115$ & $\$ 120$ \\
Graded Friction Course) & & $(18)$ & $(15)$ & $(15)$ & $(17)$ \\
Jointed Plain Concrete Pavement & CY & $\$ 637$ & $\$ 433$ & $\$ 283$ & $\$ 146$ \\
& & $(47)$ & $(51)$ & $(53)$ & $(51)$ \\
Jointed Plain Concrete Pavement & $\mathrm{CY}$ & $\$ 1,091$ & $\$ 792$ & $\$ 658$ & $\$ 385$ \\
(Rapid Setting) & & $(28)$ & $(16)$ & $(25)$ & $(20)$ \\
Lean Concrete Base & CY & $\$ 379$ & $\$ 292$ & $\$ 199$ & $\$ 145$ \\
& & $(134)$ & $(124)$ & $(118)$ & $(125)$ \\
Lean Concrete Base (Rapid & $\mathrm{CY}$ & $\$ 821$ & $\$ 520$ & $\$ 375$ & $\$ 341$ \\
Setting) & & $(28)$ & $(27)$ & $(28)$ & $(22)$ \\
\hline
\end{tabular}

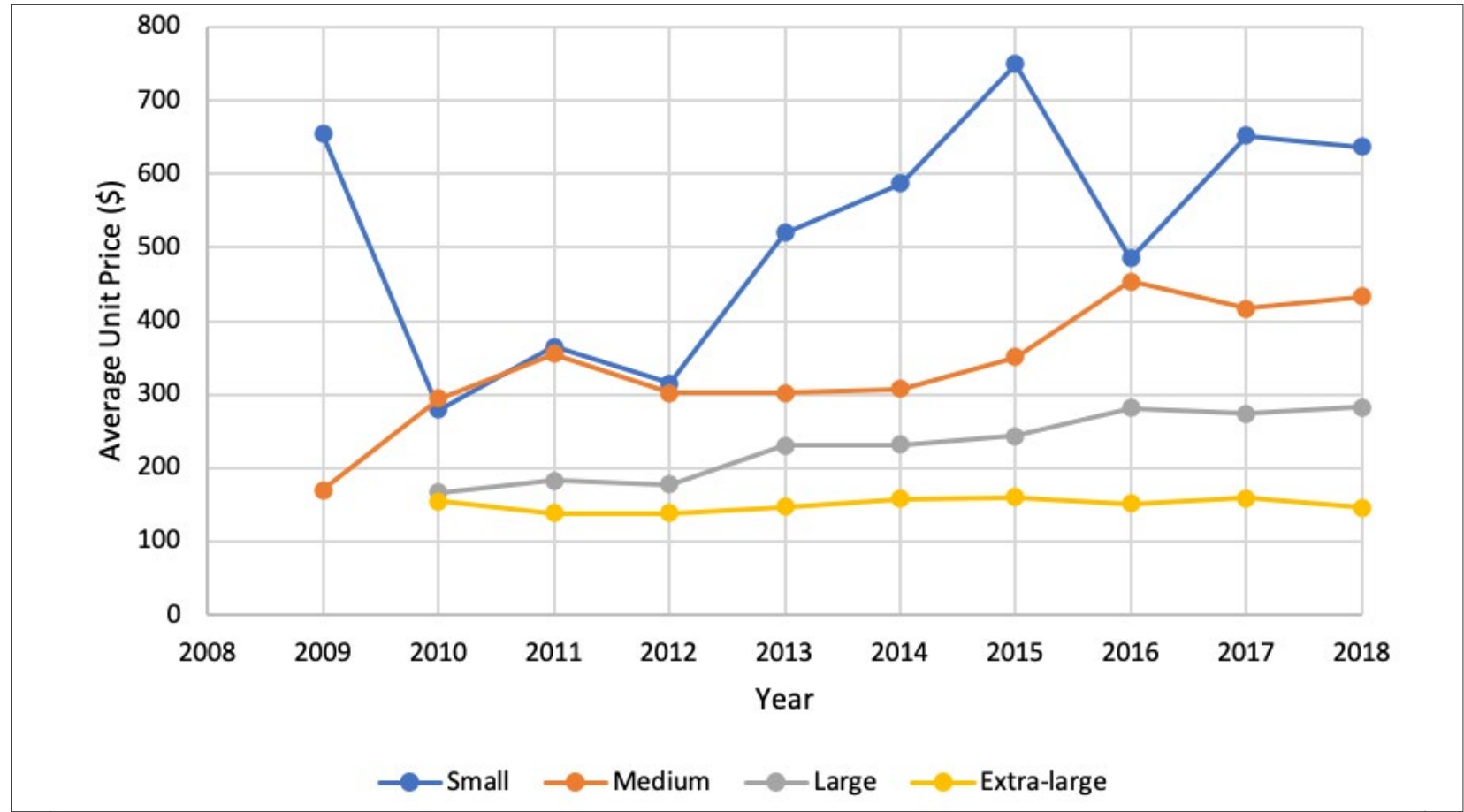

Figure 9. Average Unit Prices of Joint Plain Concrete Pavement by Project Size (2008-2018) 


\section{Multiple Regression Models}

The previous sections presented the trends in pavement material unit price by geographic location and climate region, time-series trends for socio-economic variables, and variation in unit price of pavement materials by project size. In view of the observed trends and critical variables, the research team employed multiple regression models to predict the unit price of pavement materials for use in LCCA for future M\&R projects in California. The four socio-economic parameters were included as continuous independent variables, and the project size (small, medium, large, and extra-large) was included as a discrete independent variable in the multiple regression models. The project size variable was considered as a binomial variable, that is, with any one project size being true and assigned a value of one, all other project sizes were assigned a value of zero. The unit price of a pavement material was set as the dependent variable.

Table 19 shows the R-squared values and the coefficients of the variables in the multiple regression models. The $\mathrm{R}$-squared values are in the range between 0.40005 (Lean Concrete Base) and 0.8735 (Road Excavation). The models for some materials resulted in low R-squared values due to lack of unit price information or the small number of the projects in each project size category.

In the model development process, several models showed a decreasing or unrealistically increasing trend in the future years because of large variaions of insufficient data points from the past years. For example, the model for Class 2 Aggregate Subbase predicts a decreasing pattern for the future unit prices due to the decreasing trend in the past ten years. Due to the unique pattern of the average unit price of this variable, the multiple regression model predicts a decreasing pattern in the future. Therefore, for the Class 2 Aggregate Subbase, the research team recommends using the average unit price in the latest year to calculate the future M\&R project cost instead of using the multiple regression model result. Similarly, the models for three materials-HMA Open Graded, RHMA Open Graded, and JPCP (RSC)-are not recommended for use in predicting the unit price for the future M\&R activities because these models predict unrealistically high values in the future, compared to the other materials' unit costs, possible due to insufficient data points. The average unit price data for these materials were only available for the past 4-5 years, possibly contributing to the unrealistic results of the regression models. For an example, the predicted unit prices of the HMA Open Graded at the year 2069 were 15 to 20 times higher than the unit prices at the year 2019 because the HMA Open Grded had only two to four data points per project size group. For these three materials, the research team suggests using the average unit prices in the latest year for calculating the future M\&R activity costs instead of using its multiple regression model until additional years of unit price data are available. The authors expect the unit price data will become large enough to update the models for these three materials in next five years as they are used more often recently. Although these three pavement materials were not shown in a small number of projects in the past $4-5$ years, the authors still grouped them into the four categories by project size because the unit prices for the small size projects were higher than the unit prices for the large and extra-large projects. 
Except for the four materials identified (Class 2 Aggregate Subbase, HMA Open Graded, RHMA Open Graded, JPCP (RSC)), the multiple regression models predict realistic unit prices of pavement materials for LCCA for future M\&R activities when the trend of the future predicted unit price values were compared to the trend of the past unit price values. The predicted unit prices at the $50^{\text {th }}$ year within a range between 150 and 400 percent of the unit prices at the $1^{\text {st }}$ year (base year) were resulted in the pavement items with a large number of projects. For example, the multiple regression models for HMA-A and JPCP predict a realistic unit price by project size for the future 50 years from the independent variable values predicted by the ARIMA model (Figure 10 and 11). The use of such results highlights the usefulness of the approach in this research to obtain more realistic values of pavement material unit prices for accurate LCCA.

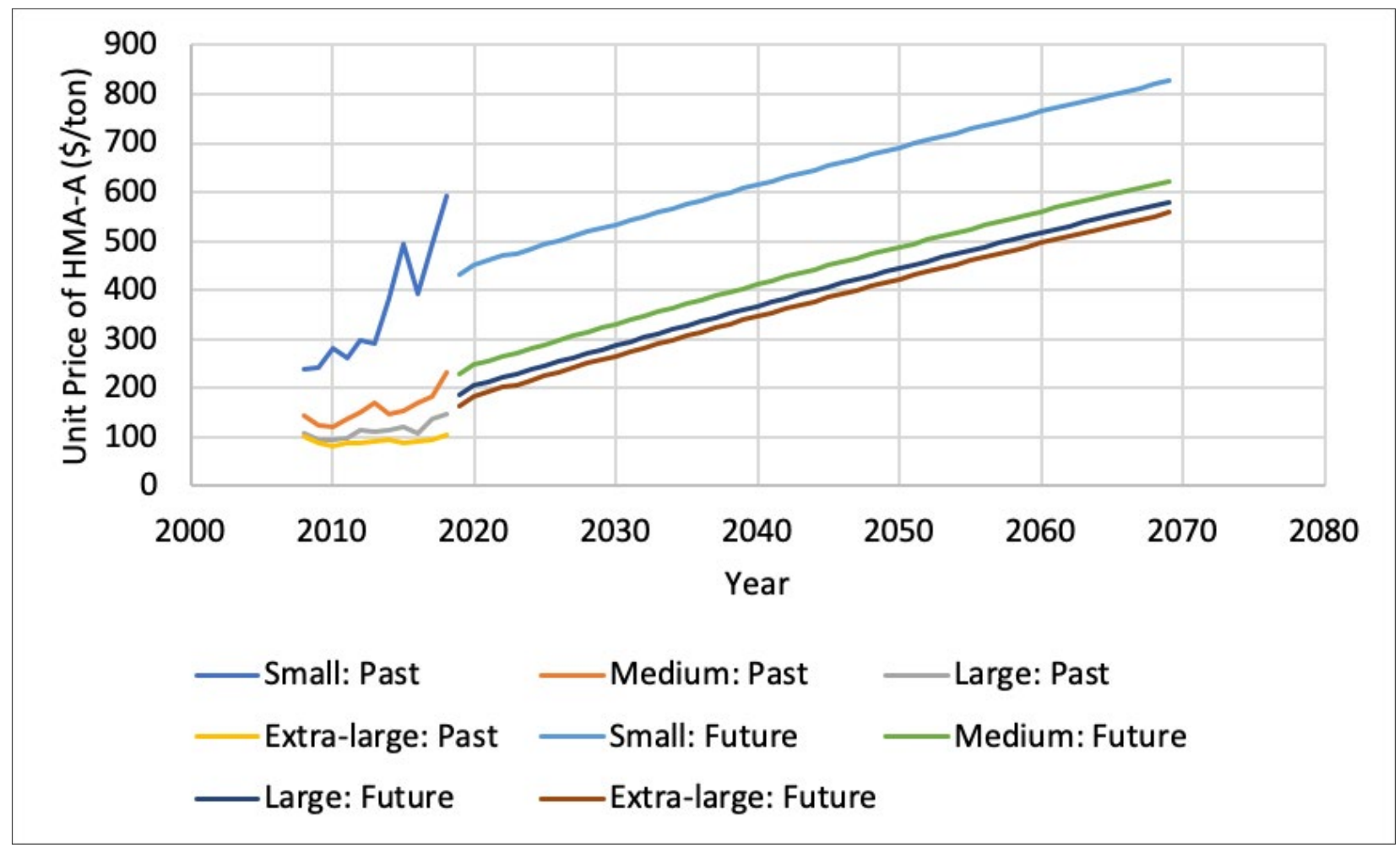

Figure 10. The Unit Price of HMA-A for the Past (Collected) and the Future (Predicted by Project Size) 


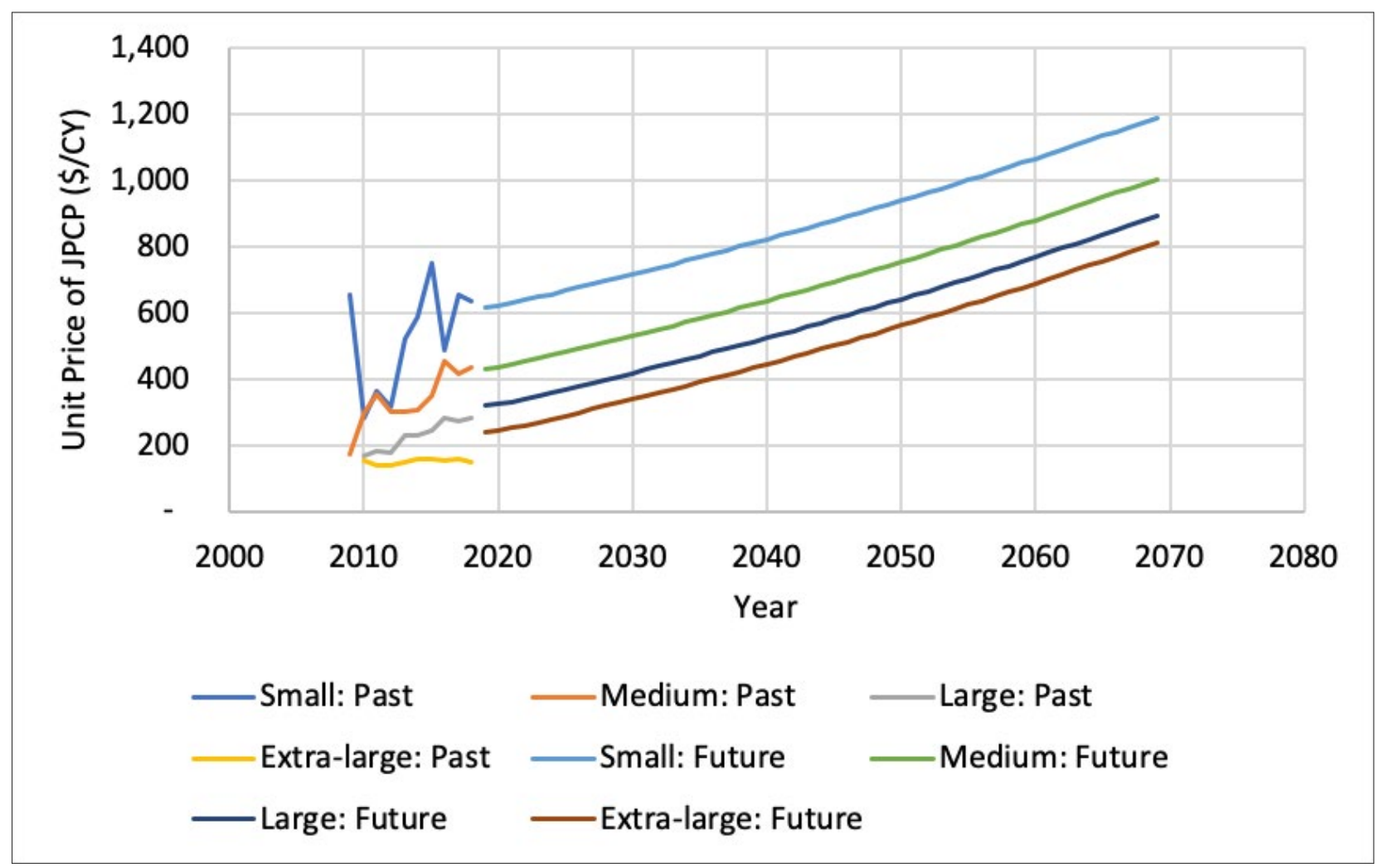

Figure 11. The Unit Price of JPCP for the Past (Collected) and the Future (Predicted by Project Size) 


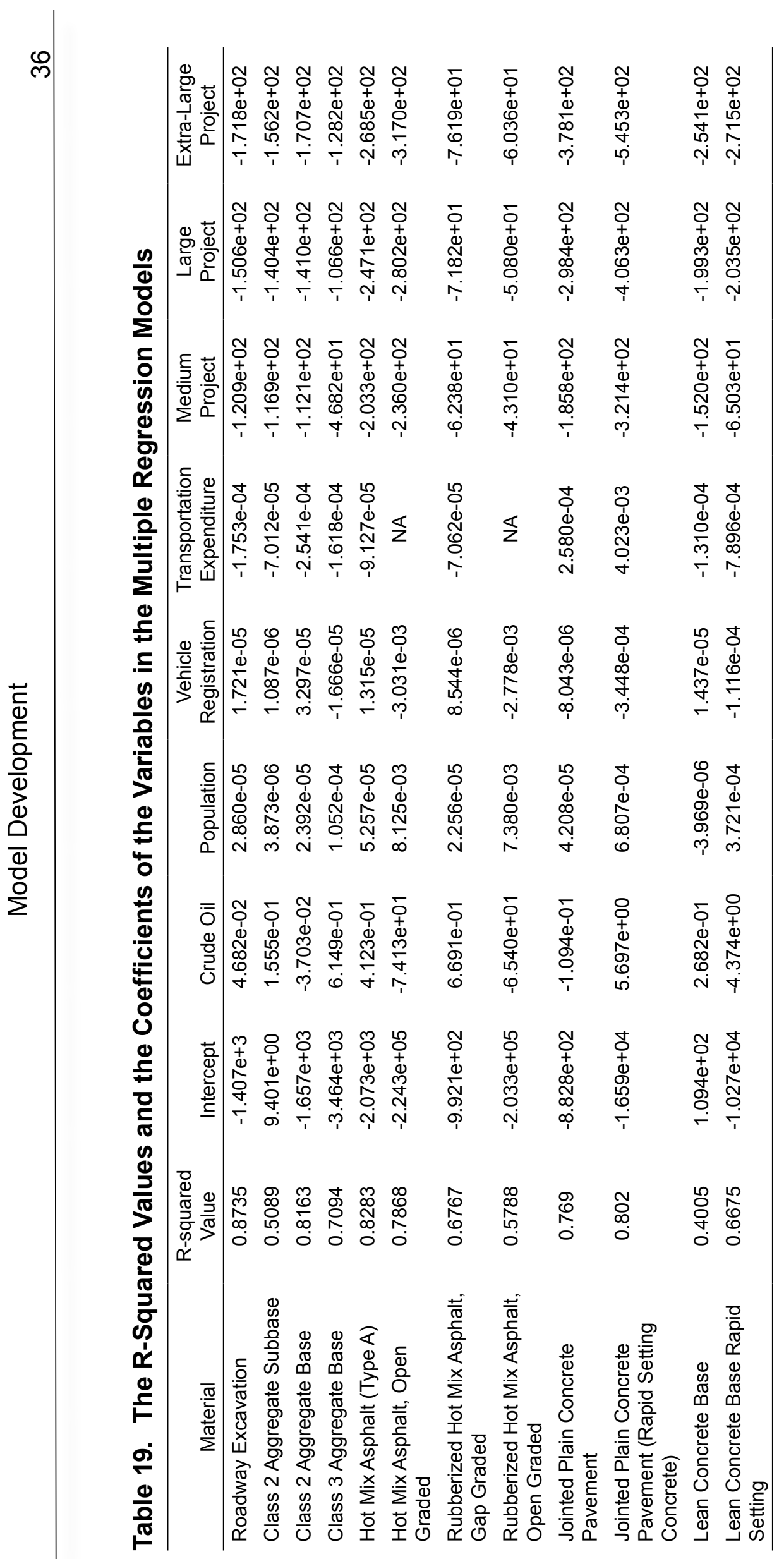




\section{LCCA CASE STUDY}

To evaluate the results of the data analysis and statistical models developed in this research, a life cycle cost analysis case study was completed using the predicted unit price values of pavement materials. The LCCA results computed with predicted unit price values were compared with LCCA results that used uniform unit prices. In this case study, agency costs of the future M\&R were included in the life cycle cost for eachthe alternative: HMA-A with 20-year design life and JPCP with 40-year design life, but road user costs were excluded in the comparison because road user costs are not associated with unit prices.

\section{DESCRIPTION OF THE CASE STUDY}

A pavement rehabilitation project on Interstate 80 in the Sacramento region was selected as a case study in this research with some modifications to represent the typical pavement rehabilitation project. Some relevant information about the case study is described as follows:

- The project length was 9.6 lane-miles on an eight-lane section;

- Two alternatives were compared in LCCA:

1. Mill and overlay with hot mix asphalt (HMA) with 20-year design life, and

2. Lane replacement Jointed Plain Concrete Pavement (JPCP) with 40-year design life;

- The rehabilitation start year was assumed to be 2020 and the LCCA period was 55 years ending in 2075;

- A four-percent annual discount rate (reflecting interest and inflation rates) was assumed in net present value calculation for the entire LCCA period (55 years).

Caltrans' LCCA procedure manual contains the future M\&R schedule for pavement material types, project types, climate region, and maintenance service levels., 7 In this case study, the future M\&R schedules for both alternatives were determined using the automatic M\&R sequence selection function in RealCost CA2.5.4. Tables 20 and 21 show the sequence of future M\&R activities, years of action, annualized maintenance cost, and activity service years for Alternative 1 (HMA) and Alternative 2 (JPCP), respectively, determined by the M\&R sequence selection in RealCost CA2.5.4. 
Table 20. Future M\&R Schedule of HMA Rehabilitation

\begin{tabular}{ccccc}
\hline $\begin{array}{c}\text { Activity } \\
\text { Number }\end{array}$ & $\begin{array}{c}\text { Activity } \\
\text { Name }\end{array}$ & $\begin{array}{c}\text { Year of } \\
\text { Action }\end{array}$ & $\begin{array}{c}\text { Annualized Maintenance } \\
\text { Cost (\$/lane-mile) }\end{array}$ & $\begin{array}{c}\text { Activity } \\
\text { Service Life (year) }\end{array}$ \\
\hline 1 & Rehab HMA & 0 & 2,700 & 18 \\
2 & CAPM HMA & 18 & 1,100 & 5 \\
3 & Rehab HMA & 23 & 2,700 & 18 \\
4 & CAPM HMA & 41 & 1,100 & 5 \\
5 & Rehab HMA & 46 & 2,700 & 18 \\
\hline
\end{tabular}

Table 21. Future M\&R Schedule of JPCP Rehabilitation

\begin{tabular}{ccccc}
\hline $\begin{array}{c}\text { Activity } \\
\text { Number }\end{array}$ & $\begin{array}{c}\text { Activity } \\
\text { Name }\end{array}$ & $\begin{array}{c}\text { Year of } \\
\text { Action }\end{array}$ & $\begin{array}{c}\text { Annualized Maintenance } \\
\text { Cost (\$/lane-mile) }\end{array}$ & $\begin{array}{c}\text { Activity } \\
\text { Service Life (year) }\end{array}$ \\
\hline 1 & Rehab JPCP & 0 & 800 & 45 \\
2 & CAPM CPR C & 45 & 3,000 & 5 \\
3 & CAPM CPR B & 50 & 1,500 & 10 \\
\hline
\end{tabular}

\section{UNIT PRICE OF PAVEMENT MATERIALS}

Based on the M\&R schedules determined in the previous section, the activity years of the future rehabilitation (REHAB) and capital maintenance (CAPM) projects for each alternative were decided. Caltrans calls major maintenance projects for restoring or repairing pavement as CAPM projects. Two separate LCCA were executed by using (1) the uniform unit prices without consideration of the project size and activity years; (2) the predicted unit prices by project size in the corresponding activity years.

For Alternative 1, $\$ 183 /$ ton was used as both the uniform and the predicted unit price for HMA rehabilitation (extra-large project) in 2020. The predicted unit price of HMA increased over time; $\$ 404 /$ ton was used for calculating the maintenance (medium size project) cost in 2028. When a four-percent annual discount rate was applied, the Net Present Value (NPV) of the uniform unit price of HMA for maintenance was $\$ 90 /$ ton, but the NPV of the predicted unit price of HMA for maintenance (medium project) was \$199/ton (Table 22).

For Alternative 2, $\$ 243 / \mathrm{CY}$ was used as the uniform unit price for all future JPCP M\&R activities regardless of project size. The predicted unit price used was $\$ 243 / \mathrm{CY}$ for JPCP rehabilitation in 2020 and $\$ 836 / C Y$ for JPCP maintenance (CPR C) in 2065. The NPVs of the uniform and the predicted unit prices for JPCP maintenance in 2065 were $\$ 42 / C Y$ and $\$ 143 /$ CY, respectively (Table 23). The NPV of the predicted unit price $(\$ 143 / C Y)$ was 240 percent higher than the NPV of the uniform unit price (\$42/CY) for JPCP maintenance in 2065. 
Table 22. The Uniform and the Predicted Unit Price and Net Present Values on the Activity Years for Alternative 1: HMA Rehab

\begin{tabular}{ccccc}
\hline Year & $\begin{array}{c}\text { Uniform Unit Price of } \\
\text { HMA (\$/ton) }\end{array}$ & $\begin{array}{c}\text { Predicted Unit Price } \\
\text { of HMA (\$/ton) }\end{array}$ & $\begin{array}{c}\text { Uniform Unit Price of } \\
\text { HMA, NPV (\$/ton) }\end{array}$ & $\begin{array}{c}\text { Predicted Unit Price } \\
\text { of HMA, NPV (\$/ton) }\end{array}$ \\
\hline 2020 & 183 & 183 & 183 & 183 \\
2038 & 183 & 404 & 90 & 199 \\
2043 & 183 & 370 & 74 & 150 \\
2061 & 183 & 568 & 37 & 114 \\
2066 & 183 & 537 & 30 & 88 \\
\hline
\end{tabular}

Table 23. The Uniform and the Predicted Unit Price and Net Present Values on the Activity Years for Alternative 2: JPCP Rehab

\begin{tabular}{ccccc}
\hline Year & $\begin{array}{c}\text { Uniform Unit Price of } \\
\text { JPCP }(\$ / C Y)\end{array}$ & $\begin{array}{c}\text { Predicted Unit Price } \\
\text { of JPCP }(\$ / C Y)\end{array}$ & $\begin{array}{c}\text { Uniform Unit Price of } \\
\text { JPCP, NPV }(\$ / \text { ton })\end{array}$ & $\begin{array}{c}\text { Predicted Unit Price } \\
\text { of JPCP, NPV (\$/ton) }\end{array}$ \\
\hline 2020 & 243 & 243 & 243 & 243 \\
2065 & 460 & 836 & 42 & 143 \\
\hline
\end{tabular}

\section{LIFE CYCLE AGENCY COSTS}

The life cycle agency costs of Alternative 1 and 2 were calculated with two sets of the unit prices (uniform and predicted) for a 50-year life cycle analysis period in RealCost CA2.5.4. The life cycle agency cost of Alternative 1 (HMA rehab) was $\$ 24.6$ million NPV with uniform unit prices and $\$ 31.2$ million NPV with predicted unit prices. Applying the predicted unit price increased the life cycle agency cost by 27 percent in NPV (Table 24).

The life cycle agency cost of Alternative 2 (JPCP rehab) was $\$ 11.83$ million NPV with uniform unit prices and $\$ 11.85$ million NPV with predicted unit prices (Table 24). The difference between the two costs was less than one percent in this case because the M\&R schedule of Alternative 2 did not include any rehabilitation activity in the future; instead, it included one small maintenance activity (CPR C in 2065).

In the LCCA results, the more cost-effective alternative was Alternative 2 (JPCP rehabilitation) when comparing the life cycle agency cost results obtained using the uniform and the predicted unit prices. The case study demonstrates the significant difference in the life cycle cost calculated by using the predicted unit prices of pavement materials by project size over time, which presents a more realistic expectation from an agency's perspective. 
Table 24. Life Cycle Agency Costs for Alternative 1: HMA Rehab

\begin{tabular}{ccccc}
\hline Year & $\begin{array}{c}\text { Agency Cost with } \\
\text { Uniform Unit Price of } \\
\text { HMA } \\
(\$ 1,000)\end{array}$ & $\begin{array}{c}\text { Agency Cost with } \\
\text { Predicted Unit Price } \\
\text { of HMA } \\
(\$ 1,000)\end{array}$ & $\begin{array}{c}\text { Agency Cost with } \\
\text { Uniform Unit Price of } \\
\text { HMA, NPV } \\
(\$ 1,000)\end{array}$ & $\begin{array}{c}\text { Agency Cost with } \\
\text { Predicted Unit } \\
\text { Price of HMA, NPV } \\
(\$ 1,000)\end{array}$ \\
\hline 2020 & 11,341 & 11,341 & 11,341 & 11,341 \\
2038 & 741 & 1,551 & 366 & 766 \\
2043 & 11,341 & 21,481 & 7,147 & 13,445 \\
2061 & 741 & 2,106 & 148 & 422 \\
2066 & 11,341 & 22,470 & 2,900 & 7,724 \\
$\begin{array}{c}\text { Total Agency Cost in } \\
\text { Life Cycle }\end{array}$ & 35,505 & 58,949 & 24,598 & 31,218 \\
\hline
\end{tabular}

Table 25. Life Cycle Agency Costs for Alternative 2: JPCP Rehab

\begin{tabular}{ccccc}
\hline Year & $\begin{array}{c}\text { Agency Cost with } \\
\text { Uniform Unit Price of } \\
\text { JPCP }(\$)\end{array}$ & $\begin{array}{c}\text { Agency Cost with } \\
\text { Predicted Unit Price } \\
\text { of JPCP }(\$)\end{array}$ & $\begin{array}{c}\text { Agency Cost with } \\
\text { Uniform Unit Price of } \\
\text { JPCP, NPV }(\$)\end{array}$ & $\begin{array}{c}\text { Agency Cost with } \\
\text { Predicted Unit Price } \\
\text { of JPCP, NPV }(\$)\end{array}$ \\
\hline 2020 & 11,794 & 11,794 & 11,794 & 11,794 \\
2065 & 241 & 338 & 41 & 58 \\
$\begin{array}{c}\text { Total Agency Cost in } \\
\text { Life Cycle }\end{array}$ & 12,035 & 12,131 & 11,835 & 11,852 \\
\hline
\end{tabular}




\section{SUMMARY AND CONCLUSION}

The main objective of this research was to develop statistical models and guidelines for using a predictive unit pricing method for pavement materials instead of deferring to uniform unit prices in LCCA for future M\&R activities. The research investigated trends in the primary pavement materials' unit price and various California socio-economic parameters over time. The primary pavement materials' unit prices in the past 20 years (1999-2018) were collected from the Caltrans Construction Contract Cost database, and trends were explored by geographical region (California districts), climate regions, and project size to identify any differences related to such factors. The results showed no significant price differences by geographical or climate region, but differences were observed according to project size. The authors categorized the unit prices of each pavement materials into four project sizes (small, medium, large, and extra-large projects), and calculated average units prices in each category. The project size was used as a binomial independent variable, and the unit prices were used as the dependent variable in multiple regression models.

The research also investigated socio-economic parameters related to highway construction to identify factors that affect and can help predict future prices of pavement materials. Various California socio-economic data were collected and after correlation analysis, four representative socio-economic parameters (national crude oil price, California population, number of vehicles registered in California, and State budget expenditure in transportation) were selected. Data on these socio-economic variables were collected for the past 20 years (1997-2018), and their future values were predicted for a 50-year LCCA period using ARIMA time-series models. The ARIMA model captured and smoothed the unique decline phenomenon of all four socio-economic parameters, except for population, during the U.S. economic recession (approximately 2008-2012), and it predicted the future values. The values of socio-economic variables (both current and predicted) were used as independent variables in multiple regression models to estimate pavement material items' unit price for the future M\&R activities in the life cycle analysis period.

Using the pavement materials' unit prices from the Caltrans database and socio-economic data collected, multiple regression models were developed to estimate the annual unit prices of each pavement material for the next 50 years (2020-2069). The R-squared values for different variables were in the range of 0.5 to 0.9 indicating that the models were able to explain at least half or more of the variation in the response variables representing a good set of results. Although some of the predictions were realistic and reasonable, others were not considered realistic or satisfactory, possibly due to smaller numbers of years in past data or small numbers of projects in size categories. For example, HMA-O's unit price was recorded for only four years from 2015 to 2018. Due to the lack of the unit price information, the average unit price was not available in some project categories during the data collection period. The authors recommend using the latest unit prices of the materials having a lack of information instead of using the predicted unit prices in the model that might be biased. Conversely, the statistical models predicted the future annual unit prices by project size for the pavement material items used in a large number of projects in the past years, such as Roadway Excavation, Class 2 Aggregate Base, HMA-A, RHMA, JPCP, and LCB. These models were verified using the unit prices in the recent projects. 
The predicted future values of pavement materials' unit prices were used in a case study to compare the differences in the results from using uniform unit prices in the current LCCA procedure. The NPVs of the life cycle agency costs calculated by the model-predicted unit prices were higher than those calculated by the uniform unit prices for two alternatives; HMA-A with 20-year design life and JPCP with 40-year design life. The results represent a more realistic and dynamic life cycle cost calculation instead of assuming fixed unit price material cost values, and signify the importance of the statistical models and methods employed in this research.

In LCCA, long-term prediction includes uncertainties due to unexpected economic trends and industry demand-supply conditions. Economic recessions and a global pandemic are examples of unexpected events which can have a significant influence on variations in material unit prices and project costs in the future. Nevertheless, the data-driven scientific approach as described in this research reduces risk caused by such uncertainties and enables practically reasonable predictions for the future. The key contribution of this research was the development of statistical models to predict the future unit prices as an alternative to the standard practice of using unifirom unit prices for the future M\&R activities. The models developed in this research can be implemented into enhancing the current LCCA procedure to predict more realistic unit prices and project costs for the future M\&R activities and thus selecting the most cost-effective alternative in LCCA. 


\section{APPENDIX A: SOCIO-ECONOMIC PARAMETERS (PAST)}

\begin{tabular}{|c|c|c|c|c|}
\hline Year & $\begin{array}{c}\text { Crude Oil Price } \\
(\$ / \text { barrel })\end{array}$ & $\begin{array}{l}\text { California } \\
\text { Population } \\
\text { (person) }\end{array}$ & $\begin{array}{c}\text { California Vehicle } \\
\text { Registration } \\
\text { (veh.) }\end{array}$ & $\begin{array}{l}\text { State Expenditure in } \\
\text { Transportation }(\$)\end{array}$ \\
\hline 1986 & 15.04 & $27,052,000$ & NA & NA \\
\hline 1987 & 19.17 & $27,717,000$ & NA & NA \\
\hline 1988 & 15.98 & $28,393,000$ & NA & NA \\
\hline 1989 & 19.64 & $29,142,000$ & NA & 12,460 \\
\hline 1990 & 24.53 & $29,828,496$ & NA & 5,978 \\
\hline 1991 & 21.50 & $30,458,613$ & NA & 36,270 \\
\hline 1992 & 20.56 & $30,987,384$ & NA & 67,751 \\
\hline 1993 & 18.45 & $31,314,189$ & NA & 93,850 \\
\hline 1994 & 17.19 & $31,523,690$ & NA & 149,903 \\
\hline 1995 & 18.44 & $31,711,849$ & NA & 173,078 \\
\hline 1996 & 22.11 & $31,962,949$ & NA & 199,170 \\
\hline 1997 & 20.61 & $32,452,789$ & $24,944,976$ & 222,035 \\
\hline 1998 & 14.45 & $32,862,965$ & $25,600,250$ & 259,744 \\
\hline 1999 & 19.26 & $33,418,578$ & $26,362,468$ & 288,993 \\
\hline 2000 & 30.30 & $34,095,209$ & $27,697,923$ & 360,420 \\
\hline 2001 & 25.95 & $34,512,742$ & $28,780,056$ & 255,717 \\
\hline 2002 & 26.12 & $34,938,290$ & $29,618,605$ & 189,737 \\
\hline 2003 & 31.12 & $35,388,928$ & $30,248,069$ & 193,084 \\
\hline 2004 & 41.44 & $35,752,765$ & $31,399,596$ & 347,468 \\
\hline 2005 & 56.49 & $35,985,582$ & $32,487,477$ & 340,382 \\
\hline 2006 & 66.02 & $36,246,822$ & $33,182,058$ & 349,855 \\
\hline 2007 & 72.32 & $36,552,529$ & $33,935,386$ & 1,039 \\
\hline 2008 & 99.57 & $36,856,222$ & $33,483,061$ & 232,433 \\
\hline 2009 & 61.65 & $37,077,204$ & $34,433,206$ & 365,332 \\
\hline 2010 & 79.40 & $37,318,481$ & $31,014,128$ & 59,045 \\
\hline 2011 & 94.87 & $37,678,534$ & $29,176,697$ & 131,470 \\
\hline 2012 & 94.11 & $38,045,271$ & $27,702,150$ & $-114,165$ \\
\hline 2013 & 97.91 & $38,425,695$ & $28,074,977$ & $-6,107$ \\
\hline 2014 & 93.26 & $38,756,940$ & $28,686,646$ & 115,255 \\
\hline 2015 & 48.69 & $39,076,128$ & $29,424,012$ & 178,929 \\
\hline 2016 & 43.14 & $39,328,337$ & $30,221,033$ & 224,626 \\
\hline 2017 & 50.88 & $39,610,556$ & $30,795,141$ & 241,488 \\
\hline 2018 & 64.94 & $39,825,181$ & $31,022,328$ & 213,914 \\
\hline
\end{tabular}




\section{APPENDIX B: SOCIO-ECONOMIC PARAMETERS (FUTURE PREDICTED)}

\begin{tabular}{|c|c|c|c|c|}
\hline Year & $\begin{array}{l}\text { Crude Oil Price } \\
\text { (\$/barrel) }\end{array}$ & $\begin{array}{l}\text { California } \\
\text { Population } \\
\text { (person) }\end{array}$ & $\begin{array}{l}\text { California Vehicle } \\
\text { Registration } \\
\text { (veh.) }\end{array}$ & $\begin{array}{c}\text { State Expenditure in } \\
\text { Transportation (\$) }\end{array}$ \\
\hline 2020 & 62.72 & $40,130,775$ & $31,659,670$ & 298,913 \\
\hline 2021 & 61.24 & $40,268,622$ & $31,874,178$ & 315,509 \\
\hline 2022 & 65.06 & $40,402,833$ & $32,088,686$ & 333,332 \\
\hline 2023 & 64.04 & $40,519,690$ & $32,303,195$ & 358,368 \\
\hline 2024 & 67.60 & $40,649,873$ & $32,517,703$ & 380,323 \\
\hline 2025 & 66.98 & $40,784,319$ & $32,732,211$ & 402,190 \\
\hline 2026 & 70.03 & $40,927,204$ & $32,946,719$ & 424,649 \\
\hline 2027 & 69.95 & $41,065,007$ & $33,161,227$ & 448,036 \\
\hline 2028 & 72.49 & $41,199,780$ & $33,375,736$ & 471,642 \\
\hline 2029 & 72.85 & $41,330,263$ & $33,590,244$ & 495,569 \\
\hline 2030 & 75.02 & $41,462,557$ & $33,804,752$ & 519,915 \\
\hline 2031 & 75.68 & $41,596,678$ & $34,019,260$ & 544,710 \\
\hline 2032 & 77.60 & $41,733,046$ & $34,233,769$ & 569,902 \\
\hline 2033 & 78.48 & $41,868,859$ & $34,448,277$ & 595,492 \\
\hline 2034 & 80.22 & $42,003,663$ & $34,662,785$ & 621,489 \\
\hline 2035 & 81.24 & $42,137,270$ & $34,877,293$ & 647,896 \\
\hline 2036 & 82.86 & $42,270,982$ & $35,091,801$ & 674,709 \\
\hline 2037 & 83.98 & $42,405,219$ & $35,306,310$ & 701,927 \\
\hline 2038 & 85.52 & $42,540,096$ & $35,520,818$ & 729,552 \\
\hline 2039 & 86.71 & $42,675,008$ & $35,735,326$ & 757,584 \\
\hline 2040 & 88.19 & $42,809,661$ & $35,949,834$ & 786,022 \\
\hline 2041 & 89.43 & $42,943,971$ & $36,164,343$ & 814,867 \\
\hline 2042 & 90.87 & $43,078,220$ & $36,378,851$ & 844,118 \\
\hline 2043 & 92.15 & $43,212,590$ & $36,593,359$ & 873,776 \\
\hline 2044 & 93.56 & $43,347,142$ & $36,807,867$ & 903,840 \\
\hline 2045 & 94.85 & $43,481,748$ & $37,022,375$ & 934,311 \\
\hline 2046 & 96.25 & $43,616,300$ & $37,236,884$ & 965,188 \\
\hline 2047 & 97.56 & $43,750,756$ & $37,451,392$ & 996,472 \\
\hline 2048 & 98.94 & $43,885,174$ & $37,665,900$ & $1,028,162$ \\
\hline 2049 & 100.26 & $44,019,614$ & $37,880,408$ & $1,060,259$ \\
\hline 2050 & 101.63 & $44,154,104$ & $38,094,917$ & $1,092,762$ \\
\hline 2051 & 102.96 & $44,288,618$ & $38,309,425$ & $1,125,672$ \\
\hline 2052 & 104.33 & $44,423,125$ & $38,523,933$ & $1,158,988$ \\
\hline 2053 & 105.66 & $44,557,606$ & $38,738,441$ & $1,192,711$ \\
\hline 2054 & 107.02 & $44,692,072$ & $38,952,949$ & $1,226,841$ \\
\hline 2055 & 108.36 & $44,826,540$ & $39,167,458$ & $1,261,376$ \\
\hline 2056 & 109.72 & $44,961,021$ & $39,381,966$ & $1,296,319$ \\
\hline 2057 & 111.06 & $45,095,511$ & $39,596,474$ & $1,331,667$ \\
\hline 2058 & 112.42 & $45,230,000$ & $39,810,982$ & $1,367,423$ \\
\hline 2059 & 113.76 & $45,364,484$ & $40,025,490$ & $1,403,585$ \\
\hline 2060 & 115.11 & $45,498,963$ & $40,239,999$ & $1,440,153$ \\
\hline
\end{tabular}


Appendix B: Socio-Economic Parameters (Future Predicted)

\begin{tabular}{ccccc}
\hline Year & $\begin{array}{c}\text { Crude Oil Price } \\
(\$ / \text { barrel) }\end{array}$ & $\begin{array}{c}\text { California } \\
\text { Population } \\
\text { (person) }\end{array}$ & $\begin{array}{c}\text { California Vehicle } \\
\text { Registration } \\
\text { (veh.) }\end{array}$ & $\begin{array}{c}\text { State Expenditure in } \\
\text { Transportation }(\$)\end{array}$ \\
\hline 2061 & 116.46 & $45,633,440$ & $40,454,507$ & $1,477,128$ \\
2062 & 117.81 & $45,767,921$ & $40,669,015$ & $1,514,509$ \\
2063 & 119.16 & $45,902,405$ & $40,883,523$ & $1,552,297$ \\
2064 & 120.51 & $46,036,889$ & $41,098,032$ & $1,590,491$ \\
2065 & 121.86 & $46,171,372$ & $41,312,540$ & $1,629,092$ \\
2066 & 123.21 & $46,305,853$ & $41,527,048$ & $1,668,099$ \\
2067 & 124.56 & $46,440,334$ & $41,741,556$ & $1,707,513$ \\
2068 & 125.91 & $46,574,816$ & $41,956,064$ & $1,747,334$ \\
2069 & 127.25 & $46,709,298$ & $42,170,573$ & $1,787,560$ \\
\hline
\end{tabular}




\section{APPENDIX C: AVERAGE UNIT PRICES OF THE PRIMARY PAVEMENT MATERIALS USED IN FOR FUTURE M\&R ACTIVITIES IN LCCA}

ROADWAY EXCAVATION (UNIT: \$/CY)

\begin{tabular}{ccccc}
\hline Year & Small Project & Medium Project & LargeProject & Extra-Large Project \\
\hline 1999 & 174 & 76 & 35 & 17 \\
2000 & 154 & 55 & 32 & 18 \\
2001 & 181 & 63 & 33 & 19 \\
2002 & 189 & 58 & 36 & 17 \\
2003 & 207 & 58 & 39 & 21 \\
2004 & 157 & 100 & 50 & 27 \\
2005 & 262 & 98 & 62 & 31 \\
2006 & 348 & 122 & 75 & 36 \\
2007 & 98 & 67 & 35 \\
2008 & 325 & 63 & 38 & 26 \\
2009 & 221 & 47 & 29 & 20 \\
2010 & 131 & 48 & 24 & 16 \\
2011 & 124 & 52 & 28 & 15 \\
2012 & 141 & 37 & 15 \\
2013 & 143 & 60 & 34 & 17 \\
2014 & 152 & 52 & 46 & 21 \\
2015 & 173 & 54 & 48 & 19 \\
2016 & 172 & 94 & 48 & 21 \\
2017 & 265 & 82 & 55 & 24 \\
2018 & 207 & 115 & 60 & 30 \\
\hline
\end{tabular}




\section{CLASS 1 AGGREGATE SUBBASE (UNIT: \$/CY)}

\begin{tabular}{ccccc}
\hline Year & Small Project & Medium Project & LargeProject & Extra-Large Project \\
\hline 1999 & NA & NA & 11 & NA \\
2000 & NA & 33 & NA & NA \\
2001 & NA & NA & NA & NA \\
2002 & 217 & NA & NA & NA \\
2003 & 76 & NA & NA & NA \\
2004 & NA & NA & NA \\
2005 & NA & NA & NA & NA \\
2006 & NA & NA & NA \\
2007 & NA & NA & NA \\
2008 & No & NA & 20 & NA \\
2009 & NA & 20 & 16 \\
2010 & 63 & NA & 1 & 19 \\
2011 & 156 & NA & NA & NA \\
2012 & 84 & 30 & NA & 11 \\
2013 & 37 & NA & NA \\
2014 & NA & 19 & NA \\
2015 & NA & NA & 26 & NA \\
2016 & NA & 30 & NA & 24 \\
2017 & NA & 29 & 20 & NA \\
2018 & NA & NA & & 27 \\
\hline
\end{tabular}




\section{CLASS 2 AGGREGATE SUBBASE (UNIT: \$/CY)}

\begin{tabular}{ccccc}
\hline Year & Small Project & Medium Project & Large Project & Extra-Large Project \\
\hline 1999 & NA & 52 & 29 & 23 \\
2000 & 66 & 65 & 56 & 23 \\
2001 & 109 & 62 & 34 & 27 \\
2002 & 73 & 71 & 47 & 28 \\
2003 & 108 & 89 & 23 & 20 \\
2004 & 104 & NA & NA & NA \\
2005 & 182 & 92 & 72 & NA \\
2006 & 275 & 88 & 66 & 62 \\
2007 & 196 & 71 & 75 & 42 \\
2008 & 142 & 46 & 33 & 47 \\
2009 & 155 & 41 & 22 & 14 \\
2010 & 144 & 32 & 28 & 15 \\
2011 & 76 & 47 & 27 & 18 \\
2012 & 520 & 70 & 31 & 10 \\
2013 & 322 & 53 & 25 \\
2014 & 245 & NA & NA & 18 \\
2015 & 116 & 28 & 40 \\
2016 & 162 & 54 & 52 & 19 \\
2017 & 313 & 51 & 51 & 38 \\
2018 & 163 & 25 & 32 \\
\hline
\end{tabular}

\section{CLASS 2 AGGREGATE BASE (UNIT: \$/CY)}

\begin{tabular}{ccccc}
\hline Year & Small Project & Medium Project & LargeProject & Extra-Large Project \\
\hline 2012 & 198 & 83 & 47 & 30 \\
2013 & 123 & 73 & 56 & 35 \\
2014 & 138 & 89 & 57 & 42 \\
2015 & 179 & 101 & 67 & 39 \\
2016 & 244 & 95 & 78 & 42 \\
2017 & 246 & 134 & 102 & 49 \\
2018 & 358 & 127 & 95 & 55 \\
\hline
\end{tabular}




\section{CLASS 3 AGGREGATE SUBBASE (UNIT: \$/CY)}

\begin{tabular}{ccccc}
\hline Year & Small Project & Medium Project & Large Project & Extra-Large Project \\
\hline 2012 & 227 & 56 & 50 & 38 \\
2013 & 111 & 114 & 52 & 29 \\
2014 & 195 & 156 & 64 & 46 \\
2015 & 150 & 119 & 81 & 41 \\
2016 & 92 & 112 & 44 & 50 \\
2017 & 186 & 138 & 83 & 40 \\
2018 & 248 & 185 & 88 & 66 \\
\hline
\end{tabular}

HOT MIX ASPHALT, TYPE A (HMA-A) (UNIT: \$/TON)

\begin{tabular}{ccccc}
\hline Year & Small Project & Medium Project & Large Project & Extra-Large Project \\
\hline 2008 & 237 & 142 & 108 & 101 \\
2009 & 241 & 124 & 95 & 88 \\
2010 & 282 & 121 & 96 & 80 \\
2011 & 262 & 137 & 98 & 88 \\
2012 & 297 & 150 & 113 & 89 \\
2013 & 290 & 171 & 111 & 92 \\
2014 & 383 & 147 & 113 & 93 \\
2015 & 495 & 153 & 120 & 88 \\
2016 & 393 & 168 & 108 & 92 \\
2017 & 492 & 182 & 137 & 95 \\
2018 & 591 & 232 & 147 & 104 \\
\hline
\end{tabular}

\section{HOT MIX ASPHALT, OPEN GRADED (HMA-O) (UNIT: \$/TON)}

\begin{tabular}{ccccc}
\hline Year & Small Project & Medium Project & Large Project & Extra-Large Project \\
\hline 2015 & 309 & 172 & 147 & 100 \\
2016 & 517 & 186 & 116 & 90 \\
2017 & & 188 & 123 & 101 \\
2018 & & 179 & 162 & 109 \\
\hline
\end{tabular}


Appendix C: Average Unit Prices of the Primary Pavement Materials

\section{RUBBERIZED HOT MIX ASPHALT, TYPE A (RHMA-A) (UNIT: \$/TON)}

\begin{tabular}{ccccc}
\hline Year & Small Project & Medium Project & Large Project & Extra-Large Project \\
\hline 2008 & 173 & 117 & 106 & 112 \\
2009 & 137 & 90 & 90 & 74 \\
2010 & 184 & 85 & 95 & 97 \\
2011 & 120 & 104 & 93 & 91 \\
2012 & 130 & 105 & 96 & 105 \\
2013 & 281 & 103 & 104 & 91 \\
2014 & 182 & 114 & 107 & 102 \\
2015 & 133 & 123 & 95 & 92 \\
2016 & 164 & 112 & 102 & 95 \\
2017 & 185 & 127 & 104 & 94 \\
2018 & 210 & 132 & 118 & 108 \\
\hline
\end{tabular}

RUBBERIZED HOT MIX ASPHALT, OPEN GRADED (RHMA-O) (UNIT: \$/TON)

\begin{tabular}{ccccc}
\hline Year & Small Project & Medium Project & Large Project & Extra-Large Project \\
\hline 2015 & 160 & 108 & 91 & 83 \\
2016 & 191 & 90 & 115 & 86 \\
2017 & 113 & 105 & 98 & 93 \\
2018 & 160 & 147 & 115 & 120 \\
\hline
\end{tabular}

JOINTED PLAIN CONCRETE PAVEMENT (JPCP) (UNIT: \$/CY)

\begin{tabular}{ccccc}
\hline Year & Small Project & Medium Project & Large Project & Extra-Large Project \\
\hline 2009 & 654 & 170 & NA & NA \\
2010 & 280 & 295 & 167 & 155 \\
2011 & 365 & 356 & 183 & 139 \\
2012 & 315 & 302 & 178 & 138 \\
2013 & 520 & 302 & 231 & 148 \\
2014 & 587 & 307 & 232 & 158 \\
2015 & 750 & 350 & 244 & 160 \\
2016 & 485 & 454 & 281 & 152 \\
2017 & 653 & 417 & 274 & 159 \\
2018 & 637 & 433 & 283 & 146 \\
\hline
\end{tabular}




\section{JOINTED PLAIN CONCRETE PAVEMENT, RAPID SETTING CONCRETE (JPCP-RSC) (UNIT: \$/CY)}

\begin{tabular}{ccccc}
\hline Year & Small Project & Medium Project & Large Project & Extra-Large Project \\
\hline 2014 & 765 & 583 & 529 & 420 \\
2015 & 827 & 435 & 468 & 428 \\
2016 & 856 & 557 & 536 & 405 \\
2017 & 1,180 & 745 & 498 & 355 \\
2018 & 1,091 & 792 & 658 & 385 \\
\hline
\end{tabular}

\section{LEAN CONCRETE BASE (LCB) (UNIT: \$/CY)}

\begin{tabular}{ccccc}
\hline Year & Small Project & Medium Project & Large Project & Extra-Large Project \\
\hline 1999 & 306 & 161 & 175 & 106 \\
2000 & 199 & 205 & 142 & 74 \\
2001 & 282 & 142 & 141 & 98 \\
2002 & 366 & 183 & 140 & 118 \\
2003 & NA & 227 & 137 & 140 \\
2004 & 443 & 249 & 246 & 122 \\
2005 & 627 & 295 & 240 & 214 \\
2006 & 593 & 428 & 403 & 213 \\
2007 & 369 & 360 & 318 & 283 \\
2008 & 282 & 267 & 226 & 203 \\
2009 & 177 & 188 & 187 & 147 \\
2010 & 230 & 163 & 150 & 112 \\
2011 & 290 & 240 & 154 & 102 \\
2012 & 1,111 & 197 & 127 & 97 \\
2013 & 360 & 188 & 127 & 92 \\
2014 & 388 & 226 & 124 & 102 \\
2015 & 321 & 208 & 175 & 88 \\
2016 & 310 & 288 & 247 & 127 \\
2017 & 370 & 241 & 146 & 123 \\
2018 & 379 & 292 & 199 & 145 \\
\hline
\end{tabular}




\section{LEAN CONCRETE BASE, RAPID SETTING CONCRETE (LCB-RSC) (UNIT: \$/CY)}

\begin{tabular}{ccccc}
\hline Year & Small Project & Medium Project & Large Project & Extra-Large Project \\
\hline 2013 & 400 & 368 & 380 & 209 \\
2014 & 402 & 402 & 328 & 163 \\
2015 & 733 & 509 & 338 & 389 \\
2016 & 530 & 689 & 469 & 397 \\
2017 & 575 & 583 & 349 & 334 \\
2018 & 821 & 520 & 375 & 341 \\
\hline
\end{tabular}




\section{APPENDIX D: PREDICTED UNIT PRICES FOR FUTURE M\&R ACTIVITIES}

ROAD EXCAVATION, UNIT PRICES (\$/CY)

\begin{tabular}{|c|c|c|c|c|}
\hline Year & Small Project & Medium Project & Large Project & Extra-Large Project \\
\hline 2020 & 236 & 115 & 86 & 64 \\
\hline 2021 & 241 & 120 & 90 & 69 \\
\hline 2022 & 245 & 124 & 95 & 74 \\
\hline 2023 & 248 & 127 & 97 & 76 \\
\hline 2024 & 252 & 131 & 101 & 80 \\
\hline 2025 & 255 & 134 & 105 & 84 \\
\hline 2026 & 259 & 138 & 109 & 88 \\
\hline 2027 & 263 & 142 & 112 & 91 \\
\hline 2028 & 266 & 146 & 116 & 95 \\
\hline 2029 & 270 & 149 & 119 & 98 \\
\hline 2030 & 273 & 152 & 122 & 101 \\
\hline 2031 & 276 & 155 & 126 & 104 \\
\hline 2032 & 279 & 159 & 129 & 108 \\
\hline 2033 & 283 & 162 & 132 & 111 \\
\hline 2034 & 286 & 165 & 135 & 114 \\
\hline 2035 & 289 & 168 & 138 & 117 \\
\hline 2036 & 291 & 171 & 141 & 120 \\
\hline 2037 & 294 & 173 & 144 & 122 \\
\hline 2038 & 297 & 176 & 146 & 125 \\
\hline 2039 & 300 & 179 & 149 & 128 \\
\hline 2040 & 302 & 181 & 152 & 131 \\
\hline 2041 & 305 & 184 & 154 & 133 \\
\hline 2042 & 307 & 186 & 157 & 136 \\
\hline 2043 & 310 & 189 & 159 & 138 \\
\hline 2044 & 312 & 191 & 162 & 140 \\
\hline 2045 & 314 & 193 & 164 & 143 \\
\hline 2046 & 317 & 196 & 166 & 145 \\
\hline 2047 & 319 & 198 & 168 & 147 \\
\hline 2048 & 321 & 200 & 170 & 149 \\
\hline 2049 & 323 & 202 & 172 & 151 \\
\hline 2050 & 325 & 204 & 174 & 153 \\
\hline 2051 & 326 & 206 & 176 & 155 \\
\hline 2052 & 328 & 207 & 178 & 156 \\
\hline 2053 & 330 & 209 & 179 & 158 \\
\hline 2054 & 332 & 211 & 181 & 160 \\
\hline 2055 & 333 & 212 & 182 & 161 \\
\hline 2056 & 335 & 214 & 184 & 163 \\
\hline 2057 & 336 & 215 & 185 & 164 \\
\hline 2058 & 337 & 216 & 187 & 165 \\
\hline 2059 & 339 & 218 & 188 & 167 \\
\hline
\end{tabular}


Appendix D: Predicted Unit Prices for Future M\&R Activities

\begin{tabular}{ccccc}
\hline Year & Small Project & Medium Project & Large Project & Extra-Large Project \\
\hline 2060 & 340 & 219 & 189 & 168 \\
2061 & 341 & 220 & 190 & 169 \\
2062 & 342 & 221 & 191 & 170 \\
2063 & 343 & 222 & 192 & 171 \\
2064 & 344 & 223 & 193 & 172 \\
2065 & 345 & 224 & 194 & 173 \\
2066 & 345 & 224 & 195 & 174 \\
2067 & 346 & 225 & 195 & 174 \\
2068 & 347 & 226 & 196 & 175 \\
2069 & 347 & 226 & 197 & 175 \\
\hline
\end{tabular}




\section{CLASS 2 AGGREGATE BASE, UNIT PRICES (\$/CY)}

\begin{tabular}{|c|c|c|c|c|}
\hline Year & Small Project & Medium Project & Large Project & Extra-Large Project \\
\hline 2020 & 268 & 156 & 127 & 98 \\
\hline 2021 & 275 & 163 & 134 & 104 \\
\hline 2022 & 280 & 168 & 139 & 110 \\
\hline 2023 & 284 & 172 & 143 & 113 \\
\hline 2024 & 288 & 176 & 147 & 118 \\
\hline 2025 & 293 & 181 & 152 & 122 \\
\hline 2026 & 298 & 186 & 157 & 127 \\
\hline 2027 & 302 & 190 & 161 & 131 \\
\hline 2028 & 306 & 194 & 165 & 136 \\
\hline 2029 & 310 & 198 & 169 & 140 \\
\hline 2030 & 314 & 202 & 173 & 144 \\
\hline 2031 & 318 & 206 & 177 & 148 \\
\hline 2032 & 322 & 210 & 181 & 152 \\
\hline 2033 & 326 & 214 & 185 & 155 \\
\hline 2034 & 330 & 218 & 189 & 159 \\
\hline 2035 & 333 & 221 & 192 & 162 \\
\hline 2036 & 337 & 224 & 196 & 166 \\
\hline 2037 & 340 & 228 & 199 & 169 \\
\hline 2038 & 343 & 231 & 202 & 172 \\
\hline 2039 & 346 & 234 & 205 & 176 \\
\hline 2040 & 349 & 237 & 208 & 179 \\
\hline 2041 & 352 & 240 & 211 & 181 \\
\hline 2042 & 355 & 243 & 214 & 184 \\
\hline 2043 & 358 & 246 & 217 & 187 \\
\hline 2044 & 360 & 248 & 219 & 190 \\
\hline 2045 & 363 & 251 & 222 & 192 \\
\hline 2046 & 365 & 253 & 224 & 194 \\
\hline 2047 & 367 & 255 & 226 & 197 \\
\hline 2048 & 370 & 258 & 229 & 199 \\
\hline 2049 & 372 & 260 & 231 & 201 \\
\hline 2050 & 374 & 262 & 233 & 203 \\
\hline 2051 & 376 & 263 & 235 & 205 \\
\hline 2052 & 377 & 265 & 236 & 207 \\
\hline 2053 & 379 & 267 & 238 & 208 \\
\hline 2054 & 381 & 269 & 240 & 210 \\
\hline 2055 & 382 & 270 & 241 & 211 \\
\hline 2056 & 383 & 271 & 242 & 213 \\
\hline 2057 & 385 & 273 & 244 & 214 \\
\hline 2058 & 386 & 274 & 245 & 215 \\
\hline 2059 & 387 & 275 & 246 & 216 \\
\hline 2060 & 388 & 276 & 247 & 217 \\
\hline 2061 & 389 & 277 & 248 & 218 \\
\hline 2062 & 389 & 277 & 248 & 219 \\
\hline 2063 & 390 & 278 & 249 & 219 \\
\hline
\end{tabular}


Appendix D: Predicted Unit Prices for Future M\&R Activities

\begin{tabular}{ccccc}
\hline Year & Small Project & Medium Project & Large Project & Extra-Large Project \\
\hline 2064 & 391 & 278 & 250 & 220 \\
2065 & 391 & 279 & 250 & 220 \\
2066 & 391 & 279 & 250 & 221 \\
2067 & 392 & 279 & 251 & 221 \\
2068 & 392 & 280 & 251 & 221 \\
2069 & 392 & 280 & 251 & 221 \\
\hline
\end{tabular}




\section{CLASS 3 AGGREGATE BASE, UNIT PRICES (\$/CY)}

\begin{tabular}{|c|c|c|c|c|}
\hline Year & Small Project & Medium Project & Large Project & Extra-Large Project \\
\hline 2020 & 221 & 174 & 114 & 92 \\
\hline 2021 & 228 & 181 & 121 & 100 \\
\hline 2022 & 238 & 191 & 131 & 110 \\
\hline 2023 & 242 & 195 & 135 & 114 \\
\hline 2024 & 251 & 204 & 144 & 122 \\
\hline 2025 & 257 & 210 & 151 & 129 \\
\hline 2026 & 267 & 220 & 160 & 139 \\
\hline 2027 & 274 & 227 & 167 & 146 \\
\hline 2028 & 282 & 236 & 176 & 154 \\
\hline 2029 & 289 & 242 & 182 & 161 \\
\hline 2030 & 297 & 250 & 190 & 168 \\
\hline 2031 & 304 & 257 & 197 & 175 \\
\hline 2032 & 311 & 265 & 205 & 183 \\
\hline 2033 & 319 & 272 & 212 & 190 \\
\hline 2034 & 326 & 279 & 219 & 198 \\
\hline 2035 & 333 & 286 & 226 & 205 \\
\hline 2036 & 340 & 293 & 233 & 212 \\
\hline 2037 & 347 & 300 & 240 & 219 \\
\hline 2038 & 354 & 307 & 247 & 226 \\
\hline 2039 & 361 & 314 & 254 & 233 \\
\hline 2040 & 368 & 321 & 261 & 240 \\
\hline 2041 & 374 & 328 & 268 & 246 \\
\hline 2042 & 381 & 334 & 274 & 253 \\
\hline 2043 & 388 & 341 & 281 & 259 \\
\hline 2044 & 394 & 347 & 288 & 266 \\
\hline 2045 & 401 & 354 & 294 & 272 \\
\hline 2046 & 407 & 360 & 300 & 279 \\
\hline 2047 & 413 & 367 & 307 & 285 \\
\hline 2048 & 420 & 373 & 313 & 291 \\
\hline 2049 & 426 & 379 & 319 & 298 \\
\hline 2050 & 432 & 385 & 325 & 304 \\
\hline 2051 & 438 & 391 & 332 & 310 \\
\hline 2052 & 444 & 397 & 338 & 316 \\
\hline 2053 & 450 & 403 & 343 & 322 \\
\hline 2054 & 456 & 409 & 349 & 328 \\
\hline 2055 & 462 & 415 & 355 & 334 \\
\hline 2056 & 468 & 421 & 361 & 339 \\
\hline 2057 & 473 & 426 & 367 & 345 \\
\hline 2058 & 479 & 432 & 372 & 351 \\
\hline 2059 & 484 & 438 & 378 & 356 \\
\hline 2060 & 490 & 443 & 383 & 362 \\
\hline 2061 & 495 & 448 & 389 & 367 \\
\hline 2062 & 501 & 454 & 394 & 372 \\
\hline 2063 & 506 & 459 & 399 & 378 \\
\hline
\end{tabular}


Appendix D: Predicted Unit Prices for Future M\&R Activities

\begin{tabular}{ccccc}
\hline Year & Small Project & Medium Project & Large Project & Extra-Large Project \\
\hline 2064 & 511 & 464 & 405 & 383 \\
2065 & 516 & 469 & 410 & 388 \\
2066 & 521 & 475 & 415 & 393 \\
2067 & 526 & 480 & 420 & 398 \\
2068 & 531 & 485 & 425 & 403 \\
2069 & 536 & 489 & 430 & 408 \\
\hline
\end{tabular}




\section{HOT MIX ASPHALT, TYPE A (HMA-A), UNIT PRICES (\$/TON)}

\begin{tabular}{|c|c|c|c|c|}
\hline Year & Small Project & Medium Project & Large Project & Extra-Large Project \\
\hline 2020 & 452 & 248 & 204 & 183 \\
\hline 2021 & 460 & 256 & 212 & 191 \\
\hline 2022 & 469 & 266 & 222 & 201 \\
\hline 2023 & 476 & 272 & 229 & 207 \\
\hline 2024 & 485 & 281 & 238 & 216 \\
\hline 2025 & 492 & 289 & 245 & 224 \\
\hline 2026 & 502 & 299 & 255 & 233 \\
\hline 2027 & 510 & 307 & 263 & 241 \\
\hline 2028 & 519 & 315 & 272 & 250 \\
\hline 2029 & 526 & 323 & 279 & 258 \\
\hline 2030 & 535 & 331 & 288 & 266 \\
\hline 2031 & 543 & 339 & 295 & 274 \\
\hline 2032 & 551 & 348 & 304 & 283 \\
\hline 2033 & 559 & 356 & 312 & 291 \\
\hline 2034 & 567 & 364 & 320 & 299 \\
\hline 2035 & 575 & 372 & 328 & 307 \\
\hline 2036 & 583 & 380 & 336 & 315 \\
\hline 2037 & 591 & 388 & 344 & 323 \\
\hline 2038 & 599 & 396 & 352 & 331 \\
\hline 2039 & 607 & 404 & 360 & 338 \\
\hline 2040 & 615 & 412 & 368 & 346 \\
\hline 2041 & 623 & 419 & 376 & 354 \\
\hline 2042 & 630 & 427 & 383 & 362 \\
\hline 2043 & 638 & 435 & 391 & 370 \\
\hline 2044 & 646 & 443 & 399 & 377 \\
\hline 2045 & 654 & 450 & 406 & 385 \\
\hline 2046 & 661 & 458 & 414 & 393 \\
\hline 2047 & 669 & 465 & 422 & 400 \\
\hline 2048 & 676 & 473 & 429 & 408 \\
\hline 2049 & 684 & 481 & 437 & 415 \\
\hline 2050 & 691 & 488 & 444 & 423 \\
\hline 2051 & 699 & 495 & 452 & 430 \\
\hline 2052 & 706 & 503 & 459 & 438 \\
\hline 2053 & 714 & 510 & 466 & 445 \\
\hline 2054 & 721 & 518 & 474 & 452 \\
\hline 2055 & 728 & 525 & 481 & 460 \\
\hline 2056 & 735 & 532 & 488 & 467 \\
\hline 2057 & 743 & 539 & 496 & 474 \\
\hline 2058 & 750 & 547 & 503 & 481 \\
\hline 2059 & 757 & 554 & 510 & 488 \\
\hline 2060 & 764 & 561 & 517 & 496 \\
\hline 2061 & 771 & 568 & 524 & 503 \\
\hline 2062 & 778 & 575 & 531 & 510 \\
\hline 2063 & 785 & 582 & 538 & 517 \\
\hline
\end{tabular}


Appendix D: Predicted Unit Prices for Future M\&R Activities

\begin{tabular}{ccccc}
\hline Year & Small Project & Medium Project & Large Project & Extra-Large Project \\
\hline 2064 & 792 & 589 & 545 & 524 \\
2065 & 799 & 596 & 552 & 531 \\
2066 & 806 & 603 & 559 & 537 \\
2067 & 813 & 609 & 566 & 544 \\
2068 & 820 & 616 & 572 & 551 \\
2069 & 826 & 623 & 579 & 558 \\
\hline
\end{tabular}


Appendix D: Predicted Unit Prices for Future M\&R Activities

RUBBERIZED HOT MIX ASPHALT, GAP GRADED (RHMA), UNIT PRICES (\$/TON)

\begin{tabular}{|c|c|c|c|c|}
\hline Year & Small Project & Medium Project & Large Project & Extra-Large Project \\
\hline 2020 & 205 & 142 & 133 & 128 \\
\hline 2021 & 207 & 145 & 136 & 131 \\
\hline 2022 & 214 & 151 & 142 & 137 \\
\hline 2023 & 216 & 153 & 144 & 139 \\
\hline 2024 & 221 & 159 & 149 & 145 \\
\hline 2025 & 224 & 162 & 152 & 148 \\
\hline 2026 & 230 & 167 & 158 & 153 \\
\hline 2027 & 233 & 170 & 161 & 157 \\
\hline 2028 & 238 & 175 & 166 & 162 \\
\hline 2029 & 241 & 179 & 169 & 165 \\
\hline 2030 & 246 & 183 & 174 & 169 \\
\hline 2031 & 249 & 187 & 177 & 173 \\
\hline 2032 & 254 & 191 & 182 & 177 \\
\hline 2033 & 257 & 195 & 185 & 181 \\
\hline 2034 & 261 & 199 & 190 & 185 \\
\hline 2035 & 265 & 203 & 193 & 189 \\
\hline 2036 & 269 & 207 & 197 & 193 \\
\hline 2037 & 273 & 210 & 201 & 197 \\
\hline 2038 & 277 & 214 & 205 & 201 \\
\hline 2039 & 280 & 218 & 209 & 204 \\
\hline 2040 & 284 & 222 & 213 & 208 \\
\hline 2041 & 288 & 226 & 216 & 212 \\
\hline 2042 & 292 & 229 & 220 & 216 \\
\hline 2043 & 295 & 233 & 224 & 219 \\
\hline 2044 & 299 & 237 & 227 & 223 \\
\hline 2045 & 303 & 240 & 231 & 226 \\
\hline 2046 & 306 & 244 & 234 & 230 \\
\hline 2047 & 310 & 247 & 238 & 234 \\
\hline 2048 & 313 & 251 & 242 & 237 \\
\hline 2049 & 317 & 254 & 245 & 241 \\
\hline 2050 & 320 & 258 & 249 & 244 \\
\hline 2051 & 324 & 261 & 252 & 248 \\
\hline 2052 & 327 & 265 & 255 & 251 \\
\hline 2053 & 331 & 268 & 259 & 254 \\
\hline 2054 & 334 & 272 & 262 & 258 \\
\hline 2055 & 337 & 275 & 265 & 261 \\
\hline 2056 & 341 & 278 & 269 & 264 \\
\hline 2057 & 344 & 281 & 272 & 268 \\
\hline 2058 & 347 & 285 & 275 & 271 \\
\hline 2059 & 350 & 288 & 278 & 274 \\
\hline 2060 & 353 & 291 & 282 & 277 \\
\hline 2061 & 357 & 294 & 285 & 280 \\
\hline 2062 & 360 & 297 & 288 & 284 \\
\hline 2063 & 363 & 300 & 291 & 287 \\
\hline
\end{tabular}


Appendix D: Predicted Unit Prices for Future M\&R Activities

\begin{tabular}{ccccc}
\hline Year & Small Project & Medium Project & Large Project & Extra-Large Project \\
\hline 2064 & 366 & 304 & 294 & 290 \\
2065 & 369 & 307 & 297 & 293 \\
2066 & 372 & 310 & 300 & 296 \\
2067 & 375 & 313 & 303 & 299 \\
2068 & 378 & 316 & 306 & 302 \\
2069 & 381 & 318 & 309 & 305 \\
\hline
\end{tabular}




\section{JOINTED PLAIN CONCRETE PAVEMENT (JPCP), UNIT PRICES (\$/CY)}

\begin{tabular}{|c|c|c|c|c|}
\hline Year & Small Project & Medium Project & Large Project & Extra-Large Project \\
\hline 2020 & 622 & 436 & 323 & 243 \\
\hline 2021 & 630 & 444 & 332 & 252 \\
\hline 2022 & 638 & 452 & 340 & 260 \\
\hline 2023 & 648 & 462 & 350 & 270 \\
\hline 2024 & 657 & 471 & 359 & 279 \\
\hline 2025 & 667 & 481 & 368 & 288 \\
\hline 2026 & 676 & 491 & 378 & 298 \\
\hline 2027 & 686 & 501 & 388 & 308 \\
\hline 2028 & 696 & 510 & 398 & 318 \\
\hline 2029 & 706 & 520 & 408 & 328 \\
\hline 2030 & 716 & 530 & 418 & 338 \\
\hline 2031 & 726 & 540 & 428 & 348 \\
\hline 2032 & 737 & 551 & 438 & 358 \\
\hline 2033 & 747 & 561 & 449 & 369 \\
\hline 2034 & 757 & 572 & 459 & 379 \\
\hline 2035 & 768 & 582 & 470 & 390 \\
\hline 2036 & 779 & 593 & 480 & 401 \\
\hline 2037 & 790 & 604 & 491 & 411 \\
\hline 2038 & 800 & 615 & 502 & 422 \\
\hline 2039 & 812 & 626 & 513 & 433 \\
\hline 2040 & 823 & 637 & 524 & 445 \\
\hline 2041 & 834 & 648 & 535 & 456 \\
\hline 2042 & 845 & 659 & 547 & 467 \\
\hline 2043 & 857 & 671 & 558 & 479 \\
\hline 2044 & 868 & 682 & 570 & 490 \\
\hline 2045 & 880 & 694 & 581 & 502 \\
\hline 2046 & 892 & 706 & 593 & 513 \\
\hline 2047 & 903 & 718 & 605 & 525 \\
\hline 2048 & 915 & 730 & 617 & 537 \\
\hline 2049 & 927 & 742 & 629 & 549 \\
\hline 2050 & 940 & 754 & 641 & 562 \\
\hline 2051 & 952 & 766 & 654 & 574 \\
\hline 2052 & 964 & 778 & 666 & 586 \\
\hline 2053 & 977 & 791 & 678 & 599 \\
\hline 2054 & 989 & 804 & 691 & 611 \\
\hline 2055 & 1,002 & 816 & 704 & 624 \\
\hline 2056 & 1,015 & 829 & 716 & 637 \\
\hline 2057 & 1,028 & 842 & 729 & 650 \\
\hline 2058 & 1,041 & 855 & 742 & 663 \\
\hline 2059 & 1,054 & 868 & 755 & 676 \\
\hline 2060 & 1,067 & 881 & 769 & 689 \\
\hline 2061 & 1,080 & 895 & 782 & 702 \\
\hline 2062 & 1,094 & 908 & 795 & 716 \\
\hline 2063 & 1,107 & 922 & 809 & 729 \\
\hline
\end{tabular}


Appendix D: Predicted Unit Prices for Future M\&R Activities

\begin{tabular}{ccccc}
\hline Year & Small Project & Medium Project & Large Project & Extra-Large Project \\
\hline 2064 & 1,121 & 935 & 823 & 743 \\
2065 & 1,135 & 949 & 836 & 757 \\
2066 & 1,149 & 963 & 850 & 771 \\
2067 & 1,163 & 977 & 864 & 784 \\
2068 & 1,177 & 991 & 878 & 799 \\
2069 & 1,191 & 1,005 & 892 & 813 \\
\hline
\end{tabular}




\section{ABBREVIATIONS AND ACRONYMS}

\begin{tabular}{ll}
\hline CAPM & Capital Maintenance \\
CPI & Consumer Price Index \\
CRCP & Continuously Reinforced Concrete Pavement \\
HMA & Hot Mix Asphalt \\
HMA-O & Hot Mix Asphalt, Open Graded \\
JPCP & Jointed Plain Concrete Pavement \\
LCB & Lean Concrete Base \\
LCCA & Life Cycle Cost Analysis \\
M\&R & Maintenance and Rehabilitation \\
RHMA & Rubberized Hot Mix Asphalt \\
RSC & Rapid Setting Concrete \\
\hline
\end{tabular}




\section{ENDNOTES}

1. Kim, C., E.-B. Lee, and J. Harvey, Enhancement of Life-Cycle Cost Analysis Tool: RealCost California Customization. 2012: Washington, D.C.

2. U.S. Department of Transportation. "Life-Cycle Cost Analysis Primer." Federal Highway Administration, Office of Asset Management, 2002.

3. U.S. Department of Transportation. "Life-Cycle Cost Analysis RealCost User Manual." Federal Highway Administration, Office of Asset Management, 2004.

4. State of California. "Life-Cycle Cost Analysis." Department of Transportationm, 2019. [cited 2019 May 25, 2019]; Available from: http://www.dot.ca.gov/hq/esc/Translab/ ope/LCCA.html.

5. Lee, E.-B., C. Kim, and J.T. Harvey, Selection of pavement for highway rehabilitation based on life-cycle cost analysis: validation of California Interstate 710 Project, Phase 1. Transportation research record, 2011. 2227(1): p. 23-32.

6. State of California. "Highway Design Manual." Department of Transportation, 2020.

7. Kim, C., et al., Automated sequence selection and cost calculation for maintenance and rehabilitation in highway Life-Cycle Cost Analysis (LCCA). International Journal of Transportation Science and Technology, 2015. 4(1): p. 61-75.

8. State of California. "Caltrans Contract Cost Data." Department of Transportation, 2019.

9. Gransberg, D.D. and K.R. Molenaar, Life-cycle cost award algorithms for design/build highway pavement projects. Journal of Infrastructure Systems, 2004. 10(4): p. 167175.

10. State of Florida. "Executive Committee Agenda Request, Procedure number 625-020010-a." Department of Transportation, Design Build Procurement and Administration, 1996.

11. Tighe, S., Guidelines for probabilistic pavement life cycle cost analysis. Transportation research record, 2001. 1769(1): p. 28-38.

12. Swei, O., J. Gregory, and R. Kirchain, Construction cost estimation: A parametric approach for better estimates of expected cost and variation. Transportation Research Part B: Methodological, 2017. 101: p. 295-305.

13. State of California. "Contract Cost Data: A Summary of Cost by Items for Highway Construction Projects." Business, Transportation and Housing Agency, Department of Transportation, 2018. 
14. U.S. Energy Information Administration. "Independent Statistics and Analysis. USA Crude Oil Spot Price per Barrel and Other Gasoline Product Prices." 2019.

15. U.S. Department of Transportation "State Transportation Statistics.: Bureau of Transportation Statistics., 2019.

16. State of California. "Demographic Forecasting Estimates." Department of Finance, 2019.

17. State of California. "Inflation, Consumer Price Index and National Deflators." Department of Finance, 2019.

18. The California Legislature's Nonpartisan Fiscal and Policy Advisor. "State Budget, Historical Data. Legislative Analyst's Office." 2019.

19. Industrial Welfare Commission (IWC). "History of California Minimum Wage. State of California." Department of Industrial Relations, 2019. 


\section{BIBLIOGRAPHY}

Caltrans Contract Cost Data. State of California Department of Transportation.

Contract Cost Data: A Summary of Cost by Items for Highway Construction Projects. 2018, State of California, Business, Transportation and Housing Agency, Department of Transportation.

Demographic Forecasting Estimates. State of California, Department of Finance.

Executive Committee Agenda Request, Procedure number 625-020-010-a, 1996. Florida Department of Transportation, Design Build Procurement and Administration: Tallahassee, FL.

Gransberg, D.D., and K.R. Molenaar. "Life-Cycle Cost Award Algorithms for Design/Build Highway Pavement Projects." Journal of Infrastructure Systems 10, no. 4 (2004): 167-175.

Highway Design Manual. State of California, Department of Transportation: 2020.

History of California Minimum Wage. State of California, Department of Industrial Relations. Industrial Welfare Commission (IWC).

Independent Statistics and Analysis. USA Crude Oil Spot Price per Barrel and Other Gasoline Product Prices. U.S. Energy Information Administration.

Inflation, Consumer Price Index and National Deflators. State of California, Department of Finance.

Kim, C., E.-B. Lee, and J. Harvey, Enhancement of Life-Cycle Cost Analysis Tool: RealCost California Customization. 2012: Washington, D.C.

Kim, C., et al. "Automated Sequence Selection and Cost Calculation for Maintenance and Rehabilitation in Highway Life-Cycle Cost Analysis (LCCA)." International Journal of Transportation Science and Technology 4, no. 1 (2015): 61-75.

Life-Cycle Cost Analysis Primer. U.S. Department of Transportation, Federal Highway Administration, Office of Asset Management: 2002.

Life-Cycle Cost Analysis RealCost User Manual. U.S. Department of Transportation, Federal Highway Administration, Office of Asset Management: 2004.

Life-Cycle Cost Analysis, State of California Department of Transportation. Available from: http://www.dot.ca.gov/hq/esc/Translab/ope/LCCA.html (accessed May 25, 2019).

Lee, E.-B., C. Kim, and J.T. Harvey. "Selection of Pavement for Highway Rehabilitation 
Based on Life-Cycle Cost Analysis: Validation of California Interstate 710 Project, Phase 1." Transportation Research Record 2227, no. 1 (2011): 23-32.

State Budget, Historical Data. Legislative Analyst's Office, The California Legislature's Nonpartisan Fiscal and Policy Advisor.

State Transportation Statistics. Bureau of Transportation Statistics, U.S. Department of Transportation.

Swei, O., J. Gregory, and R. Kirchain. "Construction Cost Estimation: A Parametric Approach for Better Estimates of Expected Cost and Variation." Transportation Research Part B: Methodological 101 (2017): 295-305.

Tighe, S. "Guidelines for Probabilistic Pavement Life Cycle Cost Analysis." Transportation Research Record 1769, no. 1 (2001): 28-38. 


\section{ABOUT THE AUTHORS}

\section{CHANGMO KIM, PHD}

Dr. Kim earned his PhD in Transportation in the Department of Civil and Environmental Engineering at the University of California, Davis in 2008. He is a project manager at the University of California Pavement Research Center at Berkeley and Davis. Dr. Kim led research projects on life cycle cost analysis (LCCA) for 15 years in California. He developed the California-customized LCCA software, RealCost CA versions, and coauthored Caltrans LCCA procedure manual. He trained LCCA implementation and provided LCCA supports to the Caltrans transportation engineers. He published over 20 papers in the peer-reviewed international journals including Transportation Research Record and ASCE Journal of Transportation, Infrastructure and Construction Management. Dr. Kim, as a part-time faculty, teaches Transportation Engineering courses in the Department of Civil Engineering at Sacramento State.

\section{GHAZAN KHAN, PHD}

Ghazan Khan is an Associate Professor in the Department of Civil Engineering at Sacramento State. His teaching and research focuses on Transportation Engineering, Traffic Operations and Safety, Geographic Information Systems (GIS), and Statistics. Dr. Khan joined the Department of Civil Engineering at Sacramento State in 2013.

Prior to joining Sacramento State, Dr. Khan worked for nine years as an Assistant Researcher, Research Associate, and Research Assistant at the Traffic Operations and Safety (TOPS) Laboratory, University of Wisconsin-Madison leading and working on various national and state sponsored research projects in the areas of Traffic Operations and Safety, Traffic Control Devices, Geographic Information Systems (GIS) and Statistical Applications in Transportation, Transportation Data and Asset Management, and so on. 


\section{MTI BOARD OF TRUSTEES}

Founder, Honorable

Norman Mineta*

Secretary (ret.),

US Department of Transportation

\section{Chair,}

Abbas Mohaddes

President \& $\mathrm{COO}$

Econolite Group Inc.

\section{Vice Chair,}

\section{Will Kempton}

Executive Director

Sacramento Transportation Authority

\section{Executive Director,}

Karen Philbrick, PhD*

Mineta Transportation Institute

San José State University

\section{Winsome Bowen}

Chief Regional Transportation

Strategy

Facebook

\section{David Castagnetti}

\section{Co-Founder}

Mehlman Castagnetti

Rosen \& Thomas

\section{Maria Cino}

Vice President

America \& U.S. Government

Relations Hewlett-Packard Enterprise

\author{
Grace Crunican** \\ Owner \\ Crunican LLC
}

\section{Donna DeMartino \\ Managing Director \\ Los Angeles-San Diego-San Luis \\ Obispo Rail Corridor Agency}

\section{Nuria Fernandez**}

General Manager \& CEO

Santa Clara Valley

Transportation Authority (VTA)

\section{John Flaherty}

Senior Fellow

Silicon Valley American

Leadership Form

\section{William Flynn * \\ President \& CEO \\ Amtrak}

\section{Rose Guilbault}

Board Member

Peninsula Corridor

Joint Powers Board

Ian Jefferies*

President \& CEO

Association of American Railroads
Diane Woodend Jones

Principal \& Chair of Board

Lea + Elliott, Inc.

David S. Kim*

Secretary

California State Transportation

Agency (CALSTA)

\section{Therese McMillan}

Executive Director

Metropolitan Transportation

Commission (MTC)

\section{Bradley Mims}

President \& CEO

Conference of Minority

Transportation Officials (COMTO)

Jeff Morales

Managing Principal

InfraStrategies, LLC

Dan Moshavi, PhD*

Dean, Lucas College and

Graduate School of Business

San José State University

Toks Omishakin*

Director

California Department of

Transportation (Caltrans)
Takayoshi Oshima

Chairman \& CEO

Allied Telesis, Inc.

Paul Skoutelas*

President \& CEO

American Public Transportation

Association (APTA)

Beverley Swaim-Staley

President

Union Station Redevelopment

Corporation

Jim Tymon*

Executive Director

American Association of

State Highway and Transportation

Officials (AASHTO)

\section{Larry Willis*}

President

Transportation Trades

Dept.,AFL-CIO

$*$ = Ex-Officio

$* *=$ Past Chair, Board of Trustees

\section{Directors}

\section{Karen Philbrick, PhD}

Executive Director

\section{Hilary Nixon, PhD}

Deputy Executive Director

\section{Asha Weinstein Agrawal, PhD}

\section{Education Director}

National Transportation Finance

Center Director

\section{Brian Michael Jenkins}

National Transportation Security

Center Director

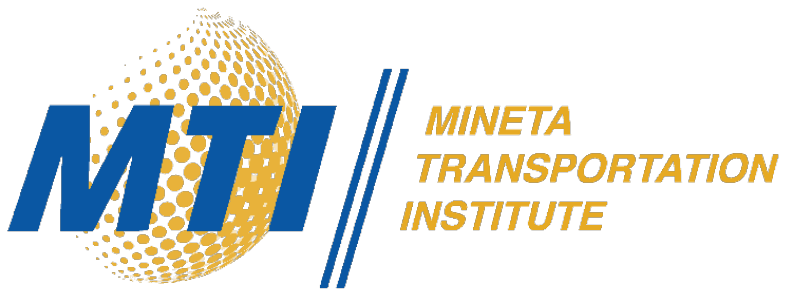

